\title{
Proximate Cause Explained: An Essay in Experimental Jurisprudence
}

\author{
Joshua Knobet \& Scott Shapirot†
}

One of the oldest debates in American jurisprudence concerns the concept of "proximate cause." According to so-called formalists, the legal concept of proximate cause is the same as the ordinary concept of "cause." The legal question of whether a cause is proximate for the purposes of establishing tort liability, therefore, is an objective matter about the external world determinable by familiar descriptive inquiry. By contrast, legal realists think that issues of proximate causation are disguised normative questions about responsibility. As the realists William Prosser and W. Page Keeton put it, proximate cause is better called "responsible cause."

Recent work in cognitive science has afforded us new insights into the way people make causal judgments that were unavailable at the time of the original debate between formalists and realists. We now have access to the results of systematic experimental studies that examine the way people ordinarily think about causation and morality. This work opens up the possibility of a very different approach to understanding the role of causation in the law-one which combines the attractive features of both formalism and realism without accepting their implausible consequences.

In addition to providing a model for interpreting the case law of proximate cause, this Article also introduces a new way of doing legal theory - a method we call "experimental jurisprudence." Experimental jurisprudence is the study of jurisprudential questions using empirical methods. Jurisprudential disputes about proximate cause are especially ripe for empirical analysis because the debate revolves around whether the legal concept of proximate cause is the same as the ordinary concept of causation. Interrogating the ordinary concept of causation, therefore, should shed light on this question.

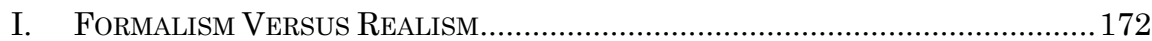

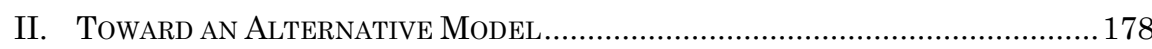

III. The Cognitive Science of Causal And Moral Judgment .........................181

A. Causal Structure and Causal Selection ............................................. 182

$\dagger$ Professor of Philosophy and Psychology and Linguistics, Yale University.

† Charles F. Southmayd Professor of Law and Professor of Philosophy, Yale University. For comments on an earlier version, we are deeply grateful to Guilherme Almeida, Fiery Cushman, Mihailis Diamantis, Ivar Hannikainen, Scott Hershovitz, Brian Leiter, James Macleod, Roseanna Sommers, Andy Summers, Kevin Tobia, John Witt, Ben Zipursky, and Gideon Yaffe. Katya Botchkina provided excellent research assistance and her philosophical suggestions were immensely helpful to us in drafting Part VI. 


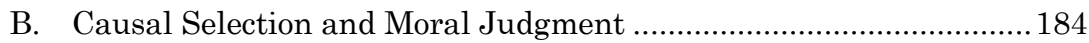

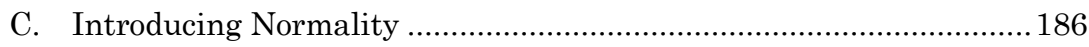

D. Patterns of Causal Judgment ..................................................... 189

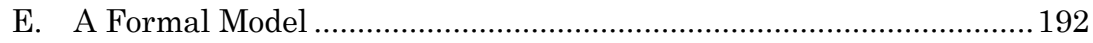

F. Normality and Disjunction.............................................................. 196

G. Summary and Implications for Proximate Cause............................ 197

IV. REALism AND Formalism ReVisited ......................................................... 199

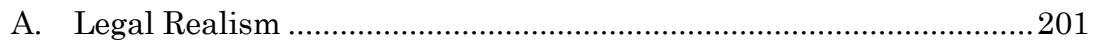

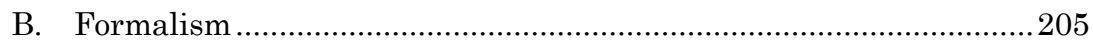

V. FolK JUdGMENTS AND LEGAL JUdGMENTS ....................................................209

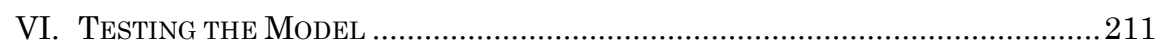

A. Intervening Causation ................................................................. 214

1. Negligence........................................................................... 215

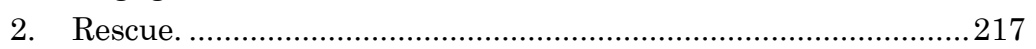

3. Medical malpractice. ............................................................. 218

4. Suicide................................................................................... 220

5. Foreseeable means. ..............................................................222

6. Problematic cases. ................................................................... 224

B. Concurrent Causation .................................................................. 229

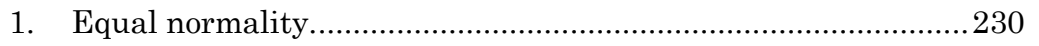

2. Unequal normality. .............................................................. 230

C. Summing Up ......................................................................... 234

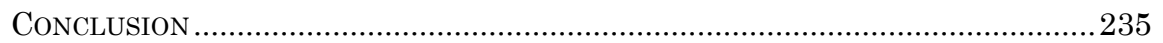

\section{INTRODUCTION}

A few days before Christmas 1924, William Markowitz sold an air rifle to Richard Kevans. Markowitz should not have made that sale. Richard Kevans was only thirteen years old and New York state law explicitly prohibited selling air rifles and ammunition "to an infant under the age of 16." 1 When Richard's mother found out, she demanded that he return the gun to Markowitz's shop. When Markowitz refused to take the rifle back, Richard's mother hid it, intending to return it to her boy when he was older. ${ }^{2}$

Six months later, Richard discovered the secreted rifle. He went down to a cellar with his friend, taking turns shooting a paper target placed over a hole in the cellar door. Unfortunately, a shot sailed through the target and hit Charles Henningsen, a seven-year-old boy who was playing on the steps on the opposite

1 Henningsen v. Markowitz, 230 N.Y.S. 313, 313 (Sup. Ct. 1928) (citing N.Y. PENAL LAW § 1896 (1911)).

2 Id. at 314 . 
side of the cellar door. Charles lost all sight in his left eye. Charles's father sued Markowitz for negligently selling a rifle to a minor and was awarded $\$ 23,000$ in damages by the court. ${ }^{3}$

The defendant had claimed that his actions were not the proximate cause of the infant's injury. ${ }^{4}$ In deciding the issue in Henningsen $v$. Markowitz, ${ }^{5}$ the New York Supreme Court relied on the following test: "[W] here defendant's active force has come to rest in a position of apparent safety, the court will follow it no longer; if some new force later combines with this condition to create harm, the result is remote from defendant's act."6

Despite the interventions of Richard, Richard's mother, Richard's friend, and Charles, the court held that the shop owner's "active force" had not yet "come to rest." 7 Markowitz's wrongdoing "continued to be potentially active" for those many months and subsequent intervening actions only served to unleash the "force which defendant had set in motion."

One need not be suspicious to be skeptical of this opinion. One reason to doubt that the court faithfully recorded its reasoning is the evident obfuscation. What precisely is an "active" force? How is an active force different from a "potentially active" force? And when exactly does an active force "come to rest in a position of apparent safety" and thus become "remote"? Since the test is inscrutable, it is difficult to see how the court could have actually used it as a premise in its reasoning.

Second, as the legal realist Leon Green argued, the opinion used the test in an inconsistent manner. ${ }^{9}$ The court borrowed the test from Professor Joseph Beale, the famed Harvard formalist, as set out in his well-known article, The Proximate Consequences of an Act. ${ }^{10}$ But, as Green pointed out, Beale applied his test very differently. ${ }^{11}$ In the same article where the borrowed test is formulated, Beale considers a case that is almost perfectly on point: "[I]f the explosive gets into the hands of an adult the defendant's force 
has ceased to be an active danger; if the explosive thereafter gets into the hands of a child, defendant is not the proximate cause of anything this child may do with it." 12 Having adopted Beale's test, the court failed to adopt Beale's application of his own test.

There is a third reason not to take the court's purported formalism at face value. The decision that the court reachednamely, to hold the criminal gun seller financially responsible ${ }^{13}$ seems like the correct resolution of the case from the moral point of view. The defendant, after all, acted irresponsibly, and it was morally appropriate for him to compensate the innocent victim. The court's ruling, in other words, is the decision one would have expected if the court were chiefly concerned with satisfying the demands of justice, not with hewing to the byzantine logic of formalism.

The confluence of these factors-obfuscation, inconsistency and acceptability-strongly suggests that the court did not take its own formalist rhetoric seriously. It is far more plausible to believe that the court ruled as it did because it judged the gun dealer to have acted reprehensibly. In this regard, Henningsen is not unique. Cases involving issues of proximate causation are among the most challenging to interpret literally. As Professor Clarence Morris noted in 1939, expressing the frustration of many torts professors: "The preceptor who aims to teach his students what courts will or should do, finds the chapter on causation a nightmare." ${ }_{14}$ The better explanation usually assumes that courts are covertly making moral judgments about the actions in question and are basing their decisions about proximate causation on them.

We are persuaded that formalism is not an acceptable interpretation of the law or of judicial behavior in proximate causation cases. Despite the rhetoric of the opinions, questions of proximate causation are not exclusively descriptive; they are often deeply normative. But we are not ready to succumb to the siren call of

12 Beale, supra note 10, at 656; see also, e.g., Pittsburgh Reduction Co. v. Horton, 113 S.W. 647, 649 (Ark. 1908) (holding that a mother granting permission to her child to play with a dynamite cap-despite neither of them recognizing it as such-broke the causal chain and rendered the company that originally possessed the cap not liable).

13 See Henningsen, 230 N.Y.S. at 317.

14 Clarence Morris, On the Teaching of Legal Cause, 39 Colum. L. REv. 1087, 1088 (1939); see also Richard W. Wright, Causation in Tort Law, 73 CALIF. L. REV. 1735, 1737 (1985) ("In all of tort law, there is no concept which has been as pervasive and yet elusive as the causation requirement."). 
the legal realist. For the realist holds a position that we believe to be extreme.

Legal realists, as we understand them, do not simply deny that the doctrine of proximate causation is descriptive in nature. Realists actually deny that there is a distinct doctrine of proximate causation. Though courts in criminal law and torts cases act as though there is such a principle, no such legal norm actually exists. On the realist construal, judges trot out this pseudoprinciple as an exercise in indirection. Rather than being used as a premise in their arguments about legal responsibility, the role of this pseudoprinciple is to disguise the moral judgment made by the judge.

Properly understood, according to the realist, to say that $X$ proximately caused $Y$ 's harm is merely to claim that $X$ is legally responsible for Y's harm. Thus, Green claimed, "the inquiry while stated in what seems to be terms of cause is in fact whether the defendant should be held responsible." 15 Professors William Prosser and W. Page Keeton put the point even more bluntly: " $[R]$ esponsible cause' would be a more appropriate term" than proximate cause. ${ }^{16}$ Appearances to the contrary, then, legal claims of proximate cause are not premises in judicial reasoning, but rather conclusions of such reasoning.

We argue that this extreme position is not warranted. Legal realists have made a strong case for the claim that judgments of proximate causation are sometimes influenced by moral judgments. One should not conclude, however, that the whole notion of proximate causation is just a smokescreen that plays no real role in judicial reasoning. There is an alternative.

Recent work in cognitive science has afforded us new insights into the way people make causal judgments that were unavailable at the time of the original debate between formalists and realists. We now have access to the results of systematic experimental studies that examine the way people ordinarily think about causation and morality. As we argue, this work opens up the possibility of a very different approach to understanding the role of causation in the law-one which combines the attractive features of both formalism and realism without accepting their implausible consequences.

15 Green, supra note 9, at 605 (emphasis in original).

16 W. Page Keeton, Dan B. Dobbs, Robert E. Keeton \& David G. Owen, Prosser AND KEETON ON THE LAW OF TORTS § 42, at 273 (5th ed. 1984). 
As we show in Part I, the traditional formulation of the debate between realism and formalism is deeply misleading. The traditional formulation assumes that there are two thingscausal judgments and moral judgments - and that the aim is to understand the relation between them. Realists affirm and formalists deny that causal judgments are determined by moral judgments.

The problem with this formulation is that it assumes that there is a single monolithic thing called "moral judgment." However, there are many different kinds of moral judgments that people are normally required to make. Faced with any given case, a person might judge that an act was morally wrong, that the agent deserves blame, that the defendant should be liable. Though these judgments are concerned in some way with moral questions, the traditional formulation of the debate lumps them all together in a single category. These different judgments are fundamentally different from each other, and they each need to be considered separately.

Once we recognize that there are different kinds of moral judgments, we see a new possibility opens up:

\section{Moral $1 \rightarrow$ Cause $\rightarrow$ Moral 2}

In other words, the suggestion is that moral judgments of one type can influence causal judgments, but these causal judgments then influence moral judgments of another type. Though the judgment on the left and the judgment on the right are both concerned with moral questions, they are distinct judgments, which play quite distinct roles in legal reasoning.

In Part II, we develop this possibility. On this proposal, the goal is to arrive at a particular sort of moral judgment, namely, a judgment as to whether the defendant should be held liable (Moral 2). As one step along the path to arriving at this judgment, people make judgments about whether the defendant was the proximate cause of the plaintiff's injury (Cause). This causal judgment is in turn influenced in part by an earlier moral judgment (Moral 1), but importantly, this first moral judgment is not the same sort of judgment as the one that people's causal judgments influence; it is a judgment of a fundamentally different type. We will have a great deal more to say about this first judgment in what follows, but for the moment, we just want to emphasize one specific point about it. This first judgment is not a judgment about whether the state should hold the defendant liable; it is concerned entirely with the moral status of the defendant's action itself (i.e., 
with questions about whether this action was itself right or wrong). Thus, on the view we will be developing, people's judgments about whether the state should hold the defendant liable are influenced by their causal judgments, which are in turn influenced by a judgment about the moral status of the defendant's action itself.

As we show, this possibility steers a middle ground between the extremes of formalism and realism. On the formalist view, one first makes the causal judgment and then uses this causal judgment as a premise in moral reasoning. On the realist view, one first makes the moral judgment and then introduces a causal judgment at the end just to offer some post hoc justification for the moral judgment one has already made. On our proposal, one first makes a moral judgment about moral rightness and wrongness. Based on this judgment, one draws a causal judgment about proximate causation. Finally, on the basis of the causal judgment, one draws a normative judgment about responsibility.

Ultimately, the only way to know whether this new model is correct is to look at actual legal decisions and legal doctrines, and we pursue that approach in Parts IV and V.

This Article not only attempts to breathe life into a tired debate about proximate causation, it also employs a new approach to resolving jurisprudential controversies. We call this approach "experimental jurisprudence." Broadly speaking, experimental jurisprudence aims to make progress on traditional questions from analytic and normative jurisprudence but to do so using a new method, namely, the use of systematic experimental studies. Specifically, research in experimental jurisprudence uses empirical studies to explore the contours of legally relevant concepts.

The studies conducted for this Article were among the first to use experimental methods to resolve jurisprudential questions. Over the past few years, however, there has been an explosion of similar research. Recent work has investigated a number of different legally relevant concepts, including the concepts of intention, responsibility, reasonableness-and of course the concept of law itself. ${ }^{17} \mathrm{~A}$ key theme in this research has been the relationship

17 For recent studies that employ a similar experimental method, see generally, for example, Raff Donelson \& Ivar R. Hannikainen, Fuller and the Folk: The Inner Morality of Law Revisited, in 3 OXFORD STUDIES IN EXPERIMENTAL PHILOSOPHY 6 (Tania Lombrozo et al. eds., 2020) (appraising Professor Lon Fuller's procedural natural law theory); Markus Kneer \& Sacha Bourgeois-Gironde, Mens Rea Ascription, Expertise and Outcome Effects: Professional Judges Surveyed, 169 COGNITION 139 (2017) (ascertaining how professional judges ascribe 
between legal concepts and the corresponding ordinary concepts. Thus, existing papers have compared the legal concept of intentional action to the ordinary concept of intentional action, ${ }^{18}$ the legal concept of consent to the ordinary concept of consent, ${ }^{19}$ and so forth. These studies suggest that many of the concepts often thought to be distinctive to the law itself are best understood to be drawn from folk psychology.

Indeed, an emerging consensus has arisen within experimental jurisprudence that Professor Kevin Tobia calls the "folk law thesis." 20 According to the folk law thesis, legal concepts share many, if not all, of the features of the corresponding ordinary concept. ${ }^{21}$ This Article lends further support to the folk law thesis. Legal judgments of proximate cause, we aim to show, actually are best understood as application of the very same criteria one finds in the ordinary folk concept.

\section{FORMALISM VERSUS REALISM}

One of the most important functions of the law is to protect the security of its subjects. Some areas-such as criminal law ${ }^{22}$ and administrative regulation ${ }^{23}$ - protect that security even when no harm has been inflicted. If I shoot at you and miss, I can be convicted of attempted murder. Punishing attempts promotes the physical security of the community by deterring additional attempts and condemning the very act of attempted homicide.

intentionality); James A. Macleod, Ordinary Causation: A Study in Experimental Statutory Interpretation, 94 IND. L.J. 957 (2019) (appraising how jury-eligible laypeople construe causal language); Christian Mott, Statutes of Limitations and Personal Identity, in 2 OXFORD STUdies IN EXPERIMENTAL PHILOSOPHY 243 (Tania Lombrozo et al. eds., 2018) (assessing whether laypeople have an intuitive sense of a statute of limitations for legal punishment); Roseanna Sommers, Commonsense Consent, 129 YALE L.J. 2232 (2020) (investigating how laypeople view consent); Kevin P. Tobia, How People Judge What Is Reasonable, 70 AlA. L. REV. 293 (2018) (arguing for a hybrid standard of reasonableness that reflects ordinary people's judgments).

18 See Kneer \& Bourgeois-Gironde, supra note 17, at 140.

19 See Sommers, supra note 17, at 2247-48.

20 Kevin P. Tobia, Law and the Cognitive Science of Ordinary Concepts, in HANDBOOK OF LAW AND THE COGNITIVE SCIENCES (forthcoming).

$21 \quad I d$.

22 E.g., Wayne R. LaFave, Substantive Criminal LaW § 11.1(b) (3d ed. 2017) ("Providing punishment for solicitation aids in the prevention of the harm which would result should the inducements prove successful.").

23 E.g., Charles H. Koch, JR. \& Richard Murphy, Administrative LaW AND PRACTICE $§ 1.12$, at $16-17$ (3d ed. 2010). 
Tort law, by contrast, protects security only when a wrong committed ripens into a harm. ${ }^{24}$ If I shoot at you and miss, you cannot sue me for intentional battery. Tort law permits the victim to extract compensation from the tortfeasor only when the tortfeasor has harmed the victim. A plaintiff may recover damages, in other words, only if the defendant breached his duty of care, and this breach was the cause of the harm that resulted. ${ }^{25}$

Traditionally, legal scholars have factored tort law's causation requirement into two components: factual and proximate causation. ${ }^{26}$ Roughly speaking, an event is a factual cause of a harm when it is causally relevant to the occurrence of the harm in question. ${ }^{27}$ Thus, if I slip deadly poison into your beer and you drink it, my action is the factual cause of your demise. If, however, you spill the beer before drinking it and get hit by a bus as you go to the store to get more beer, then my action was not a factual cause of your death because it did not contribute to the harm you suffered.

Being a factual cause is not sufficient for an event to be a legal cause. In addition, the event must be proximate to the harm. ${ }^{28} \mathrm{~A}$ factual cause is a proximate cause when its causal relevance is either of sufficient strength or bears the right relation to the harm to engender legal responsibility. Poisoning you is a proximate cause of your death; but the doctor's delivery of me as a baby would not be. For even though the doctor's actions played some causal role in your eventual poisoning, and hence is a factual cause of your death, the doctor's actions are too remote to constitute the legal cause of the harm.

Most legal theorists accept that factual causation is factual. Whether an event is causally relevant to the production of some other event is taken to be an objective, descriptive matter. The standard test for factual causation exemplifies its descriptive, nonnormative character. According to the traditional formulation, factual causation is a but-for relation: $X$ factually causes $Y$ if $Y$

24 See, e.g., RESTATEMENT (THIRD) OF TORTS $§ 5$ (AM. L. INST. 2010) (noting an actor is liable in tort for intentional physical harm only if the actor causes physical harm).

25 See, e.g., RESTATEMENT (THIRD) OF TORTS $\$ 39 \mathrm{cmt}$. d (AM. L. INST. 2010) ("[Liability is limited to when] there is a close connection between the breach of duty and the ensuing harm.”).

26 See Wex S. Malone, Ruminations on Cause-in-Fact, 9 STAN. L. REV. 60, 60 (1956).

27 See Jerry J. Phillips, Reflections on Factual Causation, 1978 WASH. U. L.Q. $661,662-63$.

28 See Malone, supra note 26, at 66. 
would not have occurred but for the occurrence of $X .{ }^{29} \mathrm{My}$ shooting you in the heart is the factual cause of your death because you would not have died had I not shot you in the heart. At least on its face, the but-for relation (also known as the relation of counterfactual dependence ${ }^{30}$ ) appears to be a descriptive, objective relation. ${ }^{31}$

Rather, the primary dispute in legal theory concerns proximate causation. Legal formalists accept, but legal realists deny, that proximate causation is as factual as factual causation. The formalist, in other words, thinks that the proximity or remoteness of a factual cause is an objective matter about the external world, determinable by familiar descriptive inquiry. It is as much a fact about the world that the doctor's delivery of me is not a proximate cause of your death as my putting the poison in your drink is a factual cause of the same event. By contrast, the legal realist thinks that issues of proximate causation are normative questions about responsibility. We judge the doctor's actions as too causally remote from your death, according to the realist, because it would be unfair to hold him responsible for my actions taken many decades later.

In the Introduction, we examined some of the reasons why legal realists have denied the facticity of proximate causation. As

29 See, e.g., RESTATEMENT (THIRD) OF TORTS $§ 26 \mathrm{cmt}$. b (AM. L. INST. 2010).

30 The term was first introduced in David Lewis, Causation, 70 J. PHIL. 556, 560 61 (1973).

31 Some legal realists have taken an extreme position and have challenged the facticity of factual causation. They have pointed out that factual causation in the law is sometimes determined by counterfactual dependence and sometimes not. If my shooting coincides with a sequoia falling on you, then my shooting is not the factual cause of your death-after all, you would have died even if I did not shoot. But if I shoot you at the same time as another person does, then both our actions are factual causes of the death even though had either of us not shot, our victim still would have died. Critics have thus charged that factual causation is not a dispassionate, objective inquiry about the world but a normative inquiry into responsibility. Overdetermination does not defeat factual causation in the latter case, on this view, because justice would be offended if each actor escaped liability as a result of the other's wrongdoing. See, e.g., Henry W. Edgerton, Legal Cause (pt. 2), 72 U. PA. L. REv. 343, 347 (1924); Malone, supra note 26, at 67; see also Ingeborg Puppe \& Richard W. Wright, Causation in the Law: Philosophy, Doctrine and Practice, in CAUSATION IN EUROPEAN TORT LAW 17, 17 (Marta Infantino \& Eleni Zervogianni eds., 2017) (finding that some theorists "assert that causation is never a purely objective, scientific issue") (citing Marta Infantino, Causation Theories and Causation Rules, in Comparative ToRT LAW: Global PeRsPeCtives 279, 298 (Mauro Bussani \& Anthony J. Sebok eds., 2015); Jonathan Schaffer, Contrastive Causation, 114 PHIL. REV. 327, 342-46, 348-49 (2005); WALTER VAN GERVEN, JEREMY F. LEVER \& Pierre larouche, Cases, Materials and Text on National, Supranational and INTERNATIONAL TORT LAW 395 (2000); CHRISTIAN VON BAR, 2 THE COMMON EUROPEAN LAW OF TORTS 435-46, 461 (2000)). 
we saw, close readings of cases such as Henningsen strongly suggest that courts do not decide proximate causation cases in a purely descriptive manner. The formalist tests that they set out are so complex and hard to follow that it is doubtful that they are ever used as stated. As Judge Henry Edgerton exclaimed after examining Beale's test and comparing it to the case law, "This is complicated; it is ambiguous; it seems arbitrary; and the authorities do not drive us to it." 32

The realists also note that courts seem to take moral wrongness into account when assigning proximate causation. The more culpable an action, the more likely a court will assign causation to that action. "[T] he intentional wrongfulness, and still more the criminality, which, as characteristics of the defendant's act, tend to lengthen the reach of legal cause, as characteristics of the intervening action tend to shorten it." 33 Thus, when a city maintained a dangerous excavation and the defendant negligently forced the plaintiff into the ditch, the city was held to be the cause of the harm; ${ }^{34}$ but when the plaintiff was intentionally pushed, the deliberate wrongdoing was enough to break the causal chain and hence the city was not held to be the proximate cause of the injury. ${ }^{35}$ The more plausible explanation for these decisions, according to the realist, is that courts are following the dictates of common sense morality: "A legal cause is a justly-attachable cause ... meaning by 'just,' not merely fair as between the parties, but socially advantageous, as serving the most important of the competing individual and social interests involved." 36

The realist position on proximate causation is not only influenced by their close readings of the case law. Just as significantly, it is motivated by the realist theory about the causes of judicial behavior. On this psychological account, judges normally seek to decide cases in accordance with their sense of justice and social

32 Henry W. Edgerton, Legal Cause (pt. 1), 72 U. PA. L. REV. 211, 223 (1924).

33 Edgerton, supra note 31 , at 364.

34 Village of Carterville v. Cook, 22 N.E. 14, 15 (Ill. 1889).

35 Alexander v. Town of New Castle, 17 N.E. 200, 202 (Ind. 1888); Milostan v. City of Chicago, 148 Ill. App. 540, 546-47 (1909).

36 Edgerton, supra note 31, at 348. Likewise, Judge William Andrews in his famous dissent in Palsgraf v. Long Island Railroad Co., 162 N.E. 99 (N.Y. 1928), claimed: "What we do mean by the word 'proximate' is that, because of convenience, of public policy, of a rough sense of justice, the law arbitrarily declines to trace a series of events beyond a certain point. This is not logic. It is practical politics." Id. at 103 (Andrews, J., dissenting). 
utility. ${ }^{37}$ Even if legal doctrine required a decision that was unjust or otherwise socially unacceptable, judges invariably interpret the rules so that the "right" result "follows." 38 Judges, after all, are people too, and seek to avoid injustice whenever possible. Thus, in torts cases, courts invariably decide for the plaintiff when they judge that the defendant is morally responsible for the harm. Likewise, in criminal cases, judges affirm convictions when they assess that the defendant is morally culpable and hence deserving of punishment.

The idea that judges decide cases in line with their moral judgments had a profound effect on the realist rejection of the formalist interpretation of proximate causation. If judges seek to do justice, why would they care about the arcane metaphysics of active forces and intervening causes? Professor Green ridiculed these concerns as the preoccupations of "legal theology" and "medieval morality." 39 While he conceded that some courts did take these metaphysical considerations seriously-memorably describing courts as according the causation doctrine "the same sanctity that young children give to Santa Claus" 40 - he thought that for the most part judges decide cases on a rational basis, namely, on the policy considerations of justice and social utility. "I am of the opinion that courts, first and last, sense these [moral] factors, even though vaguely at times, and even though the thick mists of their terminology are hard to penetrate." 41

Because under the realist theory all the heavy lifting in judicial reasoning is done by policy considerations, there is no argumentative work left for proximate causation to do. The only function of proximate causation claims is to divert attention away from the true basis of the decision:

The phraseology of causation ... has served but one useful function, and that has been to give the judges a dependable way out of difficult situations when they have made up their minds but either do not know how, or else do not take the time, to articulate their conclusions on a rational basis. ${ }^{42}$

37 See generally Brian Leiter, American Legal Realism, in THE BLACKWELl GuIDE TO The PHILOSOPHY OF LAW AND LEGAL TheORY 50 (Martin P. Golding \& William A. Edmundson eds., 2005).

38 See, e.g., Green, supra note 9, at 622-23.

39 Id. at 620-21.

$40 \quad I d$. at 620.

$41 \quad I d$. at 627.

42 Id. at 626. 
On the realist theory of judicial decision-making, then, judgments of proximate causation were not-indeed, could not bepremises in legal argument; to the contrary, they had to be the conclusions. Once the judge had decided to hold the defendant responsible, they would conclude that their action was the proximate cause of the harm.

The early legal realists were vague about the nature of the policy judgments that judges applied in proximate cause cases. Judge Edgerton, for example, described these assessments as "our free and independent sense of justice and-perhaps-[ ] the interests of society." 43 Later realists-most notably, the economic analysts of law, such as Judges Guido Calabresi ${ }^{44}$ and Richard Posner $^{45}$ and Professor Steven Shavell ${ }^{46}$-were quite explicit. On their view, the function of tort law is to maximize economic efficiency. Tort law imposes liability on wrongdoers so that people internalize the social costs of their actions. ${ }^{47}$ According to these realists, then, proximate cause judgments are simply judgments about economically efficient behavior. $X$ is the proximate cause of activity $Y$ just in cases in which deterring $X$ from engaging in $Y$ is efficient.

The realist rejection of proximate causation as a separate premise in legal reasoning and the gradual acceptance of realism by lawyers can be traced through the Restatement of Torts. The Second Restatement changed the name of proximate cause to "legal cause" in order to emphasize its normative, nonfactual nature. ${ }^{48}$ Proximate cause is not "out there" waiting to be discovered, but a creation of the law designed to impute responsibility. The Third Restatement went further by expressly advocating the abandonment of the phrases "proximate cause" and "legal cause" and the adoption of the phrase "scope of liability"; the ALI's decision reflects its judgment that "proximate cause" is policy, not cause. 49

43 Edgerton, supra note 31, at 347.

44 See Guido Calabresi, The Costs of Accidents: A Legal and Economic ANALYSIS 240-41 (1970).

45 See William M. Landes \& Richard A. Posner, Causation in Tort Law: An Economic Approach, 12 J. LEGAL STUD. 109, 110 (1983).

46 See Louis Kaplow \& Steven Shavell, Why the Legal System Is Less Efficient than the Income Tax in Redistributing Income, 23 J. LEGAL STUD. 667, 675 (1994).

47 See id. at 678.

48 Cf. ReSTATEMENT (SECOND) OF TORTS $§ 9$ (AM. L. Inst. 1965).

49 See, e.g., RESTATEMENT (THIRD) OF TORTS $§ 29$ cmt. b (AM. L. Inst. 2010) (stating that "the term 'proximate cause' is a poor one to describe limits on the scope of liability" 
Somewhat ironically, formalism about proximate causation has the same explanatory roots. Like the realists, formalists believed that judges normally rule according to their sense of justice. Formalists interpreted the doctrine of proximate causation differently, however, because they understood the requirements of justice differently. On their view, judges treat proximate causation as a metaphysically real relation because people cannot be held morally responsible for their actions unless their actions bear this objective, descriptive relation to the harm that occurred. Consider my poisoning of you because I am jealous of your success. I am morally responsible for your death not only because I intended your death and acted on that intention-I am responsible because I caused your death. The moral relation between my act and your death depends essentially on the objective factual relation between these two events. As Professor Michael Moore has written: "What we feel, and rightly feel, is that when our culpability causes serious injury to others, we are much more blameworthy than when it does not. Causation matters morally in this way." 50

As we can see, realists and formalists start from the same point but end up with very different theories. Realists deny that proximate causation is a real relation because, on their view, judges largely decide cases on the basis of moral considerations, and morality does not care for arcane metaphysics. Judgments of proximate causation, therefore, cannot be premises in judicial reasoning but must rather be conclusions to the effect that the defendant be held responsible for the harm factually caused. Formalists, on the other hand, consider proximate causation to be a real, descriptive relation because judges largely decide cases on moral considerations, and moral responsibility is essentially tied to the metaphysics of causation, arcane though they may sometimes be. Judgments of proximate causation, therefore, cannot be conclusions of judicial reasoning but rather have to be premises that generate decisions about responsibility for harm.

\section{TOWARD AN ALTERNATIVE MODEL}

Thus far, we have been discussing a debate between two different views of the relationship between causal judgments and

and recommending that factual cause be distinguished from "scope-of-liability" issues in jury instructions).

50 Michael S. Moore, Causation and Responsibility: An Essay in LaW, Morals, AND METAPHYSICS 33 (2009). 
moral judgments. On the formalist view, judges make judgments of proximate cause without taking moral considerations into account, and they then use those judgments of proximate cause as premises in a subsequent moral judgment:

\section{Proximate Cause $\rightarrow$ Moral}

This model captures the intuitive sense that judges are using claims about proximate cause to figure out whether a defendant should be held liable, but it leaves us with the somewhat strained conclusion that judges have some way of assessing proximate causation that is entirely independent of morality.

By contrast, on the realist view, judges first make a moral judgment and then use the notion of proximate causation in a purely conclusory fashion to justify the judgment they have already made:

\section{Moral $\rightarrow$ Proximate Cause}

This latter model captures the idea that moral judgments can sometimes influence assessments of proximate cause, but it then saddles us with the claim that these assessments of proximate cause play no role at all in judges' attempts to determine whether the defendant should be held liable.

A great deal has been written on the conflict between these two views, and it might at first appear that they are the only two positions worth taking seriously. After all, if we have two kinds of judgments and we know that they stand in some kind of relation, it seems that there are only so many possible ways in which this relation could work.

We want to suggest, however, that a third possibility might be worth examining:

\section{Moral $\rightarrow$ Proximate Cause $\rightarrow$ Moral}

This third model departs from both formalism and realism. The model denies that judgments of proximate causation are made purely on the basis of descriptive facts. It insists that judgments of proximate causation are sometimes influenced by moral considerations (hence the departure from formalism). Yet, at the same time, the model says that judgments of proximate causation are not just some kind of post hoc window dressing. They truly do play a role in the process leading up to moral judgment (hence the departure from realism). In other words, the model says that moral judgments can influence causal judgments but that these causal judgments in turn influence moral judgments. 
To see how this answer might be possible, it will be necessary to adopt a somewhat different way of framing the question. Our discussion thus far has been based on the assumption that there are two things - causal judgments and moral judgments-and that the aim is to understand the relation between them. But this way of framing the problem is actually deeply misleading. It is not as though there really is just a single monolithic thing called "moral judgment." Faced with any given case, people will typically make numerous different moral judgments of quite different kinds. They might judge that an act was morally wrong, that the agent deserves blame, that the defendant should be liable. Of course, all of these judgments are concerned in some way with moral questions, but it would be wrong just to lump them all together in a single category. These judgments are fundamentally different from one another, and they each need to be considered separately.

With these distinctions in place, we can introduce a further clarification to the proposed model. The model is best depicted as follows:

\section{Moral $1 \rightarrow$ Cause $\rightarrow$ Moral 2}

In other words, the suggestion is that moral judgments of one type can influence causal judgments, but these causal judgments then influence moral judgments of another type. The model therefore involves no element of circularity. Though the judgment on the left and the judgment on the right are both concerned with moral questions, they are distinct judgments, which play quite distinct roles in legal reasoning. ${ }^{51}$

Perhaps the best way to illustrate our approach is to return to the example with which we began: the court's decision in

51 Insofar as our model posits that moral judgments play a fundamental role in shaping the causal judgments that ultimately lead to judgments of legal responsibility, it resists the call made by some theorists, including Professors Jane Stapleton and Richard Wright, to "clearly distinguish" empirical from normative factors in judgments of legal responsibility. Richard W. Wright, Once More into the Bramble Bush: Duty, Causal Contribution, and the Extent of Legal Responsibility, 53 VAND. L. REV. 1071, 1081 (2001). For example, Stapleton has argued that "distilling normative principles from the 'proximate cause'/scope' case law can be done and, in the interests of legal clarity, should be done." Jane Stapleton, Choosing What We Mean by "Causation" in the Law, 73 Mo. L. REV. 433, 463 (2008). Similarly, Wright has argued that "the phrases 'proximate cause' and 'legal cause,' and other phrases that confusingly merge the empirical issue of causal contribution with the normative issue of the extent of legal responsibility ... should be replaced with terminology that clearly distinguishes these two issues." Wright, supra, at 1131. Our model, in contrast, suggests that the interplay of normative and empirical factors is a fundamental aspect of ordinary causal judgments, rather than a "confusion" stemming from insufficiently clear legal terminology. 
Henningsen. Faced with that case, one might conclude that the defendant was the cause of the plaintiff's injuries (a causal judgment), and one might also conclude that the defendant acted wrongly and should be held liable (moral judgments). What is the relationship between these various judgments? Here the formalist and the realist give opposite answers. On the formalist view, one first makes the causal judgment and then uses this causal judgment as a premise in moral reasoning. On the realist view, one first makes the moral judgment and then introduces a causal judgment at the end just to offer some post hoc justification for the moral judgment one has already made.

We suggest a view that steers a middle path between these two extremes. On this proposal, people first make a judgment about the defendant's action that in some way involves morality. Then, based in part on this first judgment, they conclude that the defendant was the proximate cause of the plaintiff's injury. Finally, based in part on this judgment of proximate cause, they conclude that the defendant should be held liable. The key point here is that although the first judgment in this sequence does involve morality, it is not in any way a judgment about whether the defendant should be held liable. It is some entirely different kind of judgment.

Ultimately, the only way to know whether this new model is correct is to look at actual legal decisions and legal doctrines, and we pursue that approach in Parts IV and V. We will start off, however, by looking to a more indirect source of evidence.

\section{The Cognitive ScIENCE OF CAUSAL AND MORAL JUdGMENT}

Both formalists and realists emphasize that judges are people and that legal reasoning is shaped in important respects by more general facts about the way people make sense of the world. ${ }^{2}$ We completely agree with this general approach, and we rely on it here. However, recent years have seen the development of a new source of information about people's ordinary understanding that simply was not available at the time of the original debate between formalists and realists. We now have access to the results of systematic experimental studies that examine the way people ordinarily think about causation and morality, and

52 See Brian Leiter, Legal Formalism and Legal Realism: What Is the Issue?, 16 LEGAL THEORY 111, 112 (2010). 
these results have the potential to offer us important clues regarding questions about how these notions are used in the law.

\section{A. Causal Structure and Causal Selection}

As we noted above, discussions of causation in the law often draw a distinction between questions of factual causation and questions of proximate causation. ${ }^{53}$ Research on causal judgments within cognitive science sometimes makes use of a roughly analogous distinction, which is there described as a distinction between causal structure and causal selection. ${ }^{54}$

Questions of causal structure are questions about which states and events depend on which other states and events. ${ }^{55}$ Thus, suppose that you are in a particularly good mood today. Your good mood might depend on the fact that it is so sunny out. (If it hadn't been so sunny, you would not have been in a good mood.) However, it should be obvious that your good mood also depends on an enormous array of other conditions. For example, it depends on the fact that you were born. (If you had never been born, you would not now be in a good mood.) It also depends on the fact that your grandparents met, the fact that there is oxygen in the Earth's atmosphere, the fact that you are not covered in poisonous spiders, and the fact of the big bang. Research in cognitive science can examine the ways in which people come to understand this whole complex web of dependencies. ${ }^{56}$

53 See supra text accompanying notes 24-26.

54 See Christopher Hitchcock, Three Concepts of Causation, 2 PHIL. ComPASs 508, 508-11 (2007). The notion of causal selection originated in the metaphysics literature within philosophy, where it was often suggested that people's ordinary causal intuitions were selective in a way that metaphysical theories of causation should not be. See JOHN Stuart Mill, 1 A System of Logic, Ratiocinative And Inductive: Being A Connected View of THE PRINCIPLEs of Evidence, AND Methods of SCIENTIFIC INVESTIGATION 36061 (London, John W. Parker 1843); Lewis, supra note 30, at 558-59.

55 Causal structure has been explored extensively within the literature on graphical causal models. See, e.g., Judea PEARL, CAUSAlity: Models, REASOning, AND InFEREnCE 12-20 (2d ed. 2009). In Part III.E., we spell out our own view using formal tools developed within this literature, but for present purposes, very little hangs on any of these issues. If existing research on causal structure turns out to be mistaken in certain respects, the points we are making about the legal doctrine of proximate cause will remain more or less unaffected.

56 For work within cognitive science on how people ordinarily infer causal structure, see, for example, Thomas L. Griffiths \& Joshua B. Tenenbaum, Structure and Strength in Causal Induction, 51 CognITIVE Psych. 334, 334-84 (2005). See also Alison Gopnik, Clark Glymour, David M. Sobel, Laura E. Schulz, Tamar Kushnir \& David Danks, A Theory of Causal Learning in Children: Causal Maps and Bayes Nets, 111 PsYCH. REV. 3,7 (2004). 
It should be noted, however, that people do not usually describe all of these relationships of dependence as relationships of causation. In the example under discussion here, people might agree with the statement, "The good weather caused your good mood," but they would probably disagree with the statements, "Your birth caused your good mood," or, "Your good mood was caused by the absence of poisonous spiders." So people must have some way of sifting through all of the factors picked out by the causal structure and figuring out which of them count as genuine causes. The question as to how people do this is known as the problem of causal selection, and it too can be studied using the methods of cognitive science.

Within the existing cognitive science literature, these judgments are normally understood not as dichotomous but as graded. ${ }^{57}$ Thus, a person might think that your good mood was mostly caused by the nice dinner you had but also partly caused by the good weather. In an example like this one, both the dinner and the weather are regarded as causes, but the dinner is seen as causal to a greater degree than the weather is. Experimental studies typically capture these graded judgments by having participants rate on a scale the degree to which a particular factor caused the outcome.

Importantly, then, the judgments explored within the cognitive science literature do not map directly onto the judgments made in the law. For example, in Henningsen, the legal question was whether the gun dealer's actions counted as a proximate cause or whether the mother's actions superseded them. ${ }^{58} \mathrm{Re}$ search in cognitive science does not directly address judgments like this one. Instead, cognitive science research would give us information about two things: the degree to which the gun dealer's actions were seen as a cause and the degree to which the mother's actions were seen as a cause. Ultimately, we will argue that research in cognitive science on these two things can shed light on legal judgments of proximate cause, but for the moment,

57 For an explicit defense of the claim that ordinary causal judgments are graded, see Joseph Y. Halpern \& Christopher Hitchcock, Graded Causation and Defaults, 66 BRIT. J. PHIL. SCI. 413, 433-36 (2015). More generally, even when there is no explicit emphasis on the claim that causal judgment is graded, cognitive science research tends to measure causal judgment on a scale and to use continuous judgments on that scale to predict other variables. See, e.g., Jonathan Phillips \& Alex Shaw, Manipulating Morality: Third-Party Intentions Alter Moral Judgments by Changing Causal Reasoning, 39 CoGNITIVE SCI. 1320, 1329-31 (2015).

58 Henningsen, 230 N.Y.S. at 315. 
we will simply focus directly on the cognitive science research itself.

\section{B. Causal Selection and Moral Judgment}

Existing research has yielded a variety of fascinating findings about the considerations that influence causal selection. Our focus here, however, will be on just one of these considerations. We will be exploring the ways in which causal selection is influenced by moral judgment. ${ }^{59}$

To get a rough sense for the contours of this effect, consider the following simple vignette:

The receptionist in the philosophy department keeps her desk stocked with pens. The administrative assistants are allowed to take the pens, but faculty members are supposed to buy their own.

The administrative assistants typically do take the pens. Unfortunately, so do the faculty members. The receptionist has repeatedly emailed them reminders that only administrative assistants are allowed to take the pens.

On Monday morning, one of the administrative assistants encounters Professor Smith walking past the receptionist's desk. Both take pens. Later that day, the receptionist needs to take an important message ... but she has a problem. There are no pens left on her desk. ${ }^{60}$

Note that the vignette has been constructed in such a way that the action of the professor and the action of the administrative assistant are almost exactly alike. Both take pens, both behave in a way that is statistically typical, and both play the same role in the causal structure. (If either action had not been performed, the problem would not have arisen.) The only major difference between them is that the professor is described as doing something

59 Within the empirical literature in cognitive science, the impact of moral judgment on causal judgment was first documented in Mark D. Alicke, Culpable Causation, $63 \mathrm{~J}$. PERSONALITY \& Soc. PsYCH. 368, 376 (1992). Within the philosophical literature, this effect has been discussed primarily in the context of causation by omission. See, e.g., Judith Jarvis Thomson, Causation: Omissions, 66 PHIL. \& Phenomenological RsCH. 81, 99 (2003); Sarah McGrath, Causation by Omission: A Dilemma, 123 PHIL. STUD. 125, 132-48 (2005).

60 Joshua Knobe \& Ben Fraser, Causal Judgment and Moral Judgment: Two Experiments, in 2 Moral Psychology: The Cognitive Science of Morality: InTUition AND DiVERSITY 441, 443 (Walter Sinnott-Armstrong ed., 2008). 
wrong, whereas the administrative assistant is described as doing exactly what she was supposed to do.

Importantly, experimental participants do not see these two agents as equally causal. Instead, participants tend to say that Professor Smith caused the problem, but that the administrative assistant did not cause the problem. ${ }^{61}$ This result suggests that people's causal selection judgments can be influenced by their judgments as to whether an agent has done something wrong.

Subsequent studies have replicated and extended this finding in numerous ways. There are studies that look at controversial moral questions and show that people's causal judgments in such cases depend on their moral views. ${ }^{62}$ There are studies showing an impact of morality in more complex causal structures, such as those involving what philosophers call "causation by omissions." 63 There are studies that examine the impact of morality while more closely controlling for considerations of statistical typicality. ${ }^{6}$ There are numerous studies demonstrating that these effects also arise in other vignettes using quite different scenarios. ${ }^{65}$ At this point, there can be little doubt that people's moral judgments do have some sort of impact on their causal judgments.

It is hard not to be struck by the parallel between this pattern in people's ordinary judgments and the pattern observed in the law. In people's ordinary judgments, we find that an action is more likely to be regarded as a cause if it is seen as in some way bad. ${ }^{6}$ Analogously, in the law, we saw that a defendant is more likely to be regarded as a proximate cause if she is seen as culpable. ${ }^{67}$ Given this striking similarity between ordinary judgment and the law, we propose to investigate the former as a way of gaining insight into the latter.

61 Id.

62 E.g., Fiery Cushman, Joshua Knobe \& Walter Sinnott-Armstrong, Moral Appraisals Affect Doing/Allowing Judgments, 108 CoGNITION 281, 282-83 (2008).

63 E.g., Pascale Willemsen, Omissions and Expectations: A New Approach to the Things We Failed to Do, 195 SYNTHESE 1587, 1592-95 (2018).

64 E.g., Craig Roxborough \& Jill Cumby, Folk Psychological Concepts: Causation, 22 PHIL. PsYch. 205, 209-10 (2009).

65 E.g., Jana Samland, Marina Josephs, Michael R. Waldmann \& Hannes Rakoczy, The Role of Prescriptive Norms and Knowledge in Children's and Adults' Causal Selection, 145 J. ExPERIMENTAL Psych. 125, 127-28 (2016); Jason Shepard \& Phillip Wolff, Intentionality, Evaluative Judgments, and Causal Structure, 35 Proc. 35TH ANN. Conf. Cognitive SCI. SoC'Y 3390, 3392-93 (2013).

66 Knobe \& Fraser, supra note 60, at 443.

67 See supra text accompanying notes $33-42$. 
So then, how exactly are we to understand the impact of moral judgment on people's ordinary, causal-selection judgments? One possible way to answer this question would be to introduce a hypothesis that is closely analogous to the realist view about proximate cause in the law. Within ordinary judgments, there is clearly a close link between causal judgment and blame judgment. Ordinarily, we might assume that this connection goes in one specific direction: the causal judgment comes first, and the blame judgment is a downstream consequence. One might now suggest that the relationship between these two judgments is sometimes reversed. On this hypothesis, the impact of moral judgment has a very simple explanation. People want to conclude that the agent deserves blame, and they therefore conclude that the agent caused the outcome. 68

We argue against this simple hypothesis. To begin with, we need to introduce a few additional concepts. Armed with these concepts, we can then formulate a new hypothesis and ask whether that hypothesis does a better job of accounting for the existing empirical data.

\section{Introducing Normality}

The first concept we need is the concept of a norm. People see some events as conforming to norms, and others as violating norms. To get clear about what this means, it will be helpful to distinguish two different kinds of norms and to explore their relationship in people's ordinary cognition. ${ }^{69}$

On one hand, there are what we might call statistical norms. These are simply facts about which things are frequent and which are infrequent. ${ }^{70}$ For example, it is a statistical fact that summers in New York tend to be hot. Thus, we might say that the norm in

68 Regardless of whether this process explains the phenomena under discussion here, there is very strong evidence in the existing empirical literature that such a process does sometimes take place and does explain certain important phenomena. Mark D. Alicke, Culpable Control and the Psychology of Blame, 126 PSYCH. BuLl. 556, 558 (2000).

69 For a classic discussion of different types of norms, see Robert B. Cialdini, Carl A. Kallgren \& Raymond R. Reno, A Focus Theory of Normative Conduct: A Theoretical Refinement and Reevaluation of the Role of Norms in Human Behavior, 24 ADVANCES EXP. Soc. PSYCH. 201, 202-23 (1991). For more recent influential treatments, see CRISTINA BICCHIERI, The Grammar of Society: The Nature AND Dynamics of Social Norms 8-34 (2005); Chandra S. Sripada \& Stephen Stich, A Framework for the Psychology of Norms, in 2 THE INNATE MIND: CUlTURE AND COGNITION 281-301 (Peter Carruthers et al. eds., 2007).

70 See Justin Sytsma, Jonathan Livengood \& David Rose, Two Types of Typicality: Rethinking the Role of Statistical Typicality in Ordinary Causal Attributions, 43 STUD. Hist. \& PHIL. BIOLOGICAL \& BiOMEDICAL SCI. 814, 815-16 (2012). 
New York is for summers to be hot, and if the weather one summer in New York happened to be cold, we feel that we were witnessing the violation of a statistical norm.

On the other hand, there are what we might call prescriptive norms. To determine whether an agent violated a prescriptive norm, one would have to go beyond just making straightforward statistical judgments and actually make a value judgment about whether the agent did anything wrong. ${ }^{71}$ For example, suppose that students consistently hand in their papers too late. Then a student who handed in her paper at the usual (late) time would not be violating a statistical norm. Still, we might judge that it was wrong of her to hand in the paper so late, and we might therefore regard her as having violated a prescriptive norm.

At least at first, one might assume that people have separate representations for these separate norms. That is, one might assume that people have a representation of the statistical norms and then, completely separately, a representation of the prescriptive norms. Though this approach might seem plausible in the abstract, research in cognitive science suggests that it is not the way people's minds actually work. Instead, people seem to integrate these two kinds of norms into undifferentiated representation of what is normal. ${ }^{72}$

As one example, consider norms about how much television to watch. When participants are asked to make a purely statistical judgment about how much TV the average person watches, they tend to guess a relatively high number. By contrast, when they are asked to make a purely prescriptive judgment about the ideal amount of TV to watch, they tend to pick a relatively low

71 Id. at 815.

72 See Adam Bear \& Joshua Knobe, Normality: Part Descriptive, Part Prescriptive, 167 COGNITION 25, 35 (2017) (reporting a series of studies that indicate that statistical and prescriptive norms are integrated into a single undifferentiated notion of the normal); Adam Bear, Samantha Bensinger, Julian Jara-Ettinger, Joshua Knobe \& Fiery Cushman, What Comes to Mind?, 194 CoGNITION 104057, at 6 (2020) (showing that the probability of something coming to mind is a function of both statistical and prescriptive norms); Jonathan Phillips \& Fiery Cushman, Morality Constrains the Default Representation of What Is Possible, 114 PROC. NAT'L ACAD. SCI. 4649, 4650 (2017) (showing that the use of natural language modals is shaped by both statistical and prescriptive norms); Tomasz Wysocki, Normality: A Two-Faced Concept, REV. PHIL. Psych., at 18-20 (Mar. 14, 2020) (showing that use of the English word "normal" reflects a blend of statistical and prescriptive norms); Steven O. Roberts, Arnold K. Ho \& Susan A. Gelman, The Role of Group Norms in Evaluating Uncommon and Negative Behaviors, 148 J. EXPERIMENTAL PSYCH. 374, 384 (2019) (showing that children blend judgments about what is statistically infrequent into their judgments about what is prescriptively wrong). 
number. ${ }^{73}$ But now consider the case in which participants are simply asked to state "a normal amount of TV to watch in a day." ${ }_{44}$ In that case, they tend to pick a number that is intermediate between the statistical average and the prescriptive ideal. ${ }^{75} \mathrm{~A}$ similar pattern emerges when participants are asked about the normal number of hours to exercise in a week, the normal number of lies to tell in a week, and the normal percentage of students who will cheat on an exam. ${ }^{76}$ In each of these domains, people seem to be integrating statistical and prescriptive considerations into a single undifferentiated notion of normality.

This framework allows us to introduce another kind of judgment people can make about actions. In addition to anything else people might think about an action, people can judge that the action is abnormal. ${ }^{77}$ In making this kind of judgment, they are not concluding that the agent is to blame for any further outcome that may ensue. Rather, they are making a judgment that is in some ways prior to, or more basic than, a judgment of blame. All they are concluding is that the action itself violated a norm.

Importantly, people will see an action as abnormal to the extent that it violates any kind of norm. Some actions will be seen as abnormal because they violate statistical norms. Others will be seen as abnormal because they violate prescriptive norms that have nothing to do with morality (as in the case of people who watch too much TV). Still others will be seen as abnormal because they violate prescriptive norms that are specifically moral. ${ }^{78}$ Thus, moral considerations play a role in judgments of abnormality, but various other considerations play precisely the same role.

With all this in the background, we can now introduce our key claim about people's ordinary causal judgments. Existing studies show that people's causal judgments can be impacted in some way by their moral judgments. We argue that this effect does not arise because people's causal judgments are impacted by their beliefs about whether an agent is to blame for the outcome. Rather, it arises because people's causal judgments are impacted by their beliefs about whether the agent's behavior is abnormal.

73 See Bear \& Knobe, supra note 72, at 29.

74 Id. at 26.

75 See id. at 28-29. For further studies showing this pattern of judgment, see Wysocki, supra note 72 , at 26.

76 Bear \& Knobe, supra note 72 , at 28 tbl.1.

77 Id. at 26.

78 Id. at 26, 33; see also Wysocki, supra note 72, at 8, 24-26. 


\section{Patterns of Causal Judgment}

The evidence for this hypothesis comes in large part from facts about the precise patterns observed in people's causal selection judgments. We therefore turn in this Section to the details of some of those patterns.

Before describing these patterns, it will be helpful to introduce some simple terminology. Consider a legal case in which one wants to know whether the defendant is the proximate cause of an outcome. One's judgment in such a case might depend in part on properties of the defendant's conduct itself and in part on properties of various alternative causal factors that may or may not supersede. Analogously, within the cognitive science literature, experimental studies have explored the ways in which people's causal judgments about a given causal factor depend on properties of that factor itself and also on properties of various alternative factors. We will consistently use the letter $C$ for the causal factor about which experimental participants are actually asked. Then we will use the letter $A$ for any other alternative causal factors that might appear in the case.

We can now define what we will call a "conjunctive case."

A case is conjunctive if there exists a causal factor $C$ and some alternative causal factor $A$, such that the outcome will occur if both of these factors are present and will not occur if either is absent. 79

The case of the professor and the pens ${ }^{80}$ is a paradigm example of a conjunctive case. In it, we have two different factors- the professor taking a pen and the administrative assistant taking a pen-such that if either of these factors had been absent, the outcome would not have occurred.

As we have seen, there is a general tendency in these cases for people's causal judgments to be impacted by their moral judgments. Specifically, factor $C$ will be regarded as more causal to the degree that it is seen as morally wrong. ${ }^{81}$ The normality-based approach now makes an important new prediction. If this effect is indeed driven by a judgment about the degree to which an event is normal or abnormal, we should be able to obtain precisely this same effect for violations of purely statistical norms.

79 See Thomas F. Icard, Jonathan F. Kominsky \& Joshua Knobe, Normality and Actual Causal Strength, 161 CoGNITION 80, 82 (2017).

80 See supra notes 59-60 and accompanying text.

81 See supra text accompanying notes 59-65. 
Importantly, existing studies suggest that this prediction is indeed borne out. ${ }^{82}$ In fact, this is the phenomenon at work in the example we first used to illustrate the concept of causal selection. Suppose that you are in a good mood and that you would not have been in such a good mood if either (a) it had not been so sunny out or (b) there had been no oxygen in the atmosphere. In such a case, it seems intuitive that your good mood was caused by the sunny day but not by the oxygen in the atmosphere. Why is that? The answer appears to come down to statistical considerations. It is more statistically infrequent for there to be a sunny day than for there to be oxygen in the atmosphere.

In short, in conjunctive cases, people tend to regard a factor as especially causal both when it is morally wrong and when it is statistically infrequent. ${ }^{3}$ The normality-based account provides a unified explanation of these two effects. ${ }^{84}$ By contrast, the blamebased account would have to say that the two effects arise for two unrelated reasons (one because of moral blame, the other because of some purely statistical kind of cognition). This is certainly a possible view, but we have at least some reason to prefer the account that provides a unified explanation.

Let's now turn to a second effect. In this second effect, people actually attribute less causation to $C$ when they regard the alternative causal factor $A$ as abnormal rather than normal. Studies consistently find this effect for moral judgments. ${ }^{85}$ Thus, if people judge that the professor was wrong to take a pen, they do not merely regard the professor's actions as more causal; they also regard the administrative assistant's actions as less causal.

An obvious initial hypothesis would be that this effect is driven by judgments of blame. When people see factor $A$ as morally wrong, they may be disinclined to blame factor $C$, and this may make them reluctant to describe factor $C$ as a cause of the outcome. Yet, though this hypothesis might initially seem plausible, we argue that it is actually incorrect. On our view, the effect is driven not by judgments about whether factor $C$ is blameworthy, but rather by judgments about whether factor $A$ is abnormal. Thus,

82 See Denis J. Hilton \& Ben R. Slugoski, Knowledge-Based Causal Attribution: The Abnormal Conditions Focus Model, 93 PSYCH. REV. 75, 82-87 (1986).

83 See Bear \& Knobe, supra note 72, at 33; see also Knobe \& Fraser, supra note 60, at 443 ; Hilton \& Slugoski, supra note 82 , at $82-87$.

84 See Bear \& Knobe, supra note 72, at 35 .

85 See, e.g., Icard et al., supra note 79 , at $81-82$. 
we predict that the effect should persist even in cases where the question about whether factor $C$ is blameworthy clearly plays no role.

Existing research provides two pieces of evidence for this claim. First, studies also show a completely parallel effect for purely statistical judgments. ${ }^{86}$ In other words, when $A$ is seen as highly infrequent or improbable, people not only regard $A$ as more causal; they also regard $C$ as less causal. ${ }^{87}$ In such cases, factor $A$ is regarded as abnormal, but the question of blame simply does not arise. Still, we continue to find the same effect on causal judgments.

Second, the effect continues to emerge even when the outcome is not itself bad. In other words, it is true that when factor $A$ is seen as morally wrong, factor $C$ is seen as less of a cause of bad outcomes that ensue, but this effect is actually quite general. Factor $C$ also ends up being seen as less of a cause of outcomes that are perfectly innocuous.

As an example, consider the following vignette:

Bill's wife, Sue, is out of town for the weekend. She leaves Bill a message that says, "I just saw this marvelous bookend. It's called a Bartlett bookend. So pretty! I'm going to go back tomorrow and get one. It will be perfect for the left side of our bookshelf."

Bill goes and visits his friend. Bill and his friend talk for a while, and when Bill asks if his friend is willing to sell the bookend, his friend tells him it's a precious heirloom and he can't part with it. Bill waits until later when his friend is in the bathroom, and slips the bookend into his bag. Finally, Bill leaves his friend's house with the stolen right-side Bartlett bookend in his bag.

Then the next day, Sue goes and buys the left-side Bartlett bookend. So, when Sue got home, they had the paired set of bookends. 88

Now ask yourself whether you agree with following statement:

Sue caused them to possess the paired set of bookends.

Note that the statement here says that Sue is the cause of a completely innocuous outcome. Thus, if you disagree with this

\footnotetext{
86 See Icard et al., supra note 79, at 81-82.

87 Id. at 81.

88 Jonathan F. Kominsky, Jonathan Phillips, Tobias Gerstenberg, David Lagnado \& Joshua Knobe, Causal Superseding, 137 Cognition 196, 200 tbl.1 (2015).
} 
statement, you are not thereby suggesting anything at all about the degree to which Sue is deserving of blame. Yet studies show that the supersession effect arises even here. Experimental participants see Sue as less causal when Bill steals the other bookend than when he buys it legally. ${ }^{89}$

Third, the effect depends in a crucial way on the causal structure of the case at hand. We have been focusing thus far on cases with conjunctive structures, but suppose we turn now to "disjunctive cases." 90 We can define this type of case as follows:

A case is disjunctive if there exists a causal factor $C$ and some alternative causal factor $A$, such that the outcome will occur if either factor is present but will not occur if both are absent. 91

In disjunctive cases, the effect completely disappears. When the alternative causal factor $A$ is seen as morally wrong, people show no tendency at all to say that factor $C$ is less causal. ${ }^{92}$ Thus, the effect observed here does not seem to be just a matter of wanting to let the agent off the hook when some other factor is to blame. It seems to be revealing something far more fundamental about how people make causal judgments.

\section{E. A Formal Model}

Within cognitive science research on these topics, one common approach is to develop formal mathematical models that predict and explain the patterns in people's judgments. ${ }^{93}$ We discuss

89 See id. at 200-01.

90 Cases of this type have long played a key role in work on causal judgment, in part because they provide a counterexample to the simple view on which outcomes must always be counterfactually dependent on their causes (i.e., on which it must be the case that if the cause had not occurred, the outcome would not have occurred). Within the philosophical literature, there have been a number of different attempts to address this issue. See, e.g., David Lewis, Causation as Influence, 97 J. PHIL. 182, 182 (2000); Joseph Y. Halpern \& Judea Pearl, Causes and Explanations: A Structural-Model Approach. Part I: Causes, 56 BRIT. J. PHIL. SCI. 843, 852-58 (2005); Jonathan Schaffer, Trumping Preemption, 97 J. PHIL. 165, 176-81 (2000). For a discussion in the context of causation in the law, see Macleod, supra note 17, at 1009-10.

91 See Icard et al., supra note 79 , at 82.

92 Id.

93 For existing research that aims to provide formal models of causal strength, see Patricia W. Cheng, From Covariation to Causation: A Causal Power Theory, 104 PsYCH. REV. 367, 377 (1997); Barbara A. Spellman, Crediting Causality, 126 J. EXPERIMENTAL Psych. GEN. 323, 327 (1997); Branden Fitelson \& Christopher Hitchcock, Probabilistic Measures of Causal Strength, in CAUSALITY IN THE SCIENCES 600, 604-05 (Phyllis M. Illari et al. eds., 2011). The effects reviewed in the previous Sections were discovered after the publication of these models, and none of them predict these specific effects. However, the model we will be presenting below is very much in the tradition of the earlier models. 
one such model here, but before we get into the details, it may be helpful to say a quick word about the role of these models in ongoing research.

Thus far, we have been talking in a very straightforward way about the patterns observed in people's causal judgments. Over the past few years, a variety of further studies have provided further evidence for these patterns, and there is a growing consensus within the literature that these patterns really do exist. ${ }^{94}$ By contrast, there is relatively little consensus about how to explain on a deeper level why these patterns are emerging. We will be considering a specific formal model—and we do think that this model provides some valuable insight-but these are difficult questions, and different researchers might well have different opinions about them. ${ }^{95}$

With that said, let's consider a formal model, originally developed by Professor Thomas Icard and colleagues, that

94 See, e.g., Tobias Gerstenberg \& Thomas Icard, Expectations Affect Physical Causation Judgments, 149 J. EXPERIMENTAL PSYCH. GEN. 599, 602-04 (2020) (showing that these effects arise even when participants are not given verbal vignettes but instead see the events occurring in a video display); Lara Kirfel, Thomas Icard \& Tobias Gerstenberg, Inference from Explanation 10-17 (2020) (unpublished manuscript) (illustrating that when people hear an explanation, they can correctly make inferences about whether the causal structure was conjunctive or disjunctive and about the normality of each factor); Paul Henne, Kevin O’Neill, Paul Bello, Sangeet Khemlani \& Felipe De Brigard, Norms Affect Prospective Causal Judgments 26 (2020) (unpublished manuscript) (demonstrating that abnormal inflation arises even for judgments about events that have not yet occurred); Paul Henne, Laura Niemi, Ángel Pinillos, Felipe De Brigard \& Joshua Knobe, A Counterfactual Explanation for the Action Effect in Causal Judgment, 190 CoGNITION 157, 157-64 (2019) (showing that omissions are regarded as less causal than actions in conjunctive cases but more causal than actions in disjunctive cases). For a review of recent empirical work on this topic, see generally Pascale Willemsen \& Lara Kirfel, Recent Empirical Work on the Relationship Between Causal Judgments and Norms, 14 PHIL. COMPASS e12562 (2019).

95 Recent work has led to the development of a number of attempts to explain the effects we have been discussing that do not involve formal mathematical models of causal strength of the type we will be discussing here. See, e.g., Justin Sytsma, Causation, Responsibility, and Typicality, REV. PHIL. \& PSYCH. 1, 22-30 (forthcoming) (arguing that the impact of statistical norms on causal judgment is itself best understood in terms of responsibility attribution); Jana Samland \& Michael R. Waldmann, How Prescriptive Norms Influence Causal Inferences, 156 COGNITION 164, 164-66 (2016) (arguing that the impact of prescriptive norms on causal judgment arises from a distinct process from the one driving the impact of statistical norms); Mark D. Alicke, David Rose \& Dori Bloom, Causation, Norm Violation, and Culpable Control, 108 J. PHIL. 670 , 689-93 (2011) (arguing that the impact of prescriptive norms is actually due to motivated reasoning and a desire to blame); Lara Kirfel \& David Lagnado, I Know What You Did Last Summer (and How Often). Epistemic States and Statistical Normality in Causal Judgments, 2019 CoGSCI 575, 580 (arguing that the effect arises because of people's inferences about the beliefs about the agents within the vignettes). 
successfully predicts all of the findings we have discussed thus far. ${ }^{96}$ The first key idea is that the probability of considering a possibility is proportional to its normality. ${ }^{97}$ When people are thinking about ways things might be, they have a high probability of considering possibilities in which things are normal and a lower probability of considering possibilities in which things are abnormal. ${ }^{98}$ The assumption is that this tendency holds quite generally, but the most important implication for present purposes is in cases in which people are concerned with causal questions. Consider a case in which people are wondering whether some event $C$ caused an outcome. As they are thinking about this issue, people might consider possibilities in which $C$ did not occur (departing in this way from the actual world) or possibilities in which $C$ did occur (just as it did in the actual world). The hypothesis is that people will be more inclined to consider possibilities of the former type when event $C$ is abnormal, while being more inclined to consider possibilities of the latter type when the event $C$ is normal.99

The second key idea is that when people are engaged in causal judgment, they engage in different cognitive processes depending on which of these two possibilities they consider. ${ }^{100}$ When people consider possibilities in which $C$ did not occur, they ask whether $C$ is necessary for the outcome. That is, they ask whether if $C$ had not occurred, the outcome would not have occurred. ${ }^{101} \mathrm{By}$ contrast, when people consider possibilities in which $C$ did occur, they ask whether $C$ is sufficient for the outcome. That is, they ask whether, given that $C$ occurred, the outcome would have occurred even if various other things in the situation had been a little bit different. 102

96 See generally Icard et al., supra note 79.

97 See id. at 85.

98 See id. Although we focus on the implications of this claim for causal judgments in particular, existing empirical research indicates that it applies far more broadly. See generally Bear et al., supra note 72, at 3; Daniel Kahneman \& Dale T. Miller, Norm Theory: Comparing Reality to Its Alternatives, 93 PSYCH. REV. 136 (1986).

99 Icard et al., supra note 79 , at 85.

100 Id. at 86.

101 The idea that causal judgments are influenced in part by judgments of necessity, understood at least broadly along these lines, has played an enormous role within in the existing literature on causation and causal reasoning. The locus classicus for the idea is Lewis, supra note 30, at 556-67. There have been numerous attempts to work out in detail the relationship between causal judgment and necessity. See, e.g., Halpern \& Pearl, supra note 90 , at 846 .

102 Icard et al., supra note 79, at 84. This notion of sufficiency is derived in large part from James Woodward, Sensitive and Insensitive Causation, 115 PHIL. REV. 1, 24-30 (2006). Existing empirical research provides evidence that people's causal intuitions are indeed 
The third key idea follows almost immediately from the first two. Consider conjunctive cases in which the outcome will only occur if events $C$ and $A$ both occur. Now consider what happens in such a case when people are trying to determine whether $C$ is sufficient for the outcome. People will regard $C$ as sufficient to the extent that they consider cases in which $A$ occurs and as insufficient to the extent that they consider cases in which $A$ does not occur. But the probability of considering cases in which $A$ occurs is itself proportional to the normality of $A$. Thus, the more $A$ is abnormal, the less people will regard $C$ as sufficient for the outcome. ${ }^{103}$

Putting all of these points together, we arrive at a specific model of people's causal judgments. On this model, the degree to which people regard some event $C$ as the cause of an outcome should be a weighted sum of the degree to which $C$ is necessary for the outcome and the degree to which $C$ is sufficient for the outcome, with the weighting determined by the normality of $C .104$ Moreover, in conjunctive cases in which an outcome will occur only when both $C$ and $A$ occur, the degree to which $C$ is regarded as sufficient for the outcome should be lower to the extent that $A$ is abnormal.

It can easily be shown that this causal strength measure predicts all three of the findings we have been discussing thus far. That is, this measure predicts that: (a) in conjunctive cases, $C$ should be regarded as more causal when it is abnormal; (b) in conjunctive cases, $C$ should be regarded as less causal when the alternative causal factor $A$ is more abnormal; and (c) in disjunctive cases, $C$ should not be regarded as less causal when an alternative causal factor $A$ is more abnormal. ${ }^{105}$

We hasten to emphasize that this formal model is unlikely to be correct in all its details and will almost certainly require

influenced by the degree to which a cause is seen as sufficient for its effect. See, e.g., Tania Lombrozo, Causal-Explanatory Pluralism: How Intentions, Functions, and Mechanisms Influence Causal Ascriptions, 61 CoGnitive PsyCH. 303, 308 (2010); Christopher Hitchcock, Portable Causal Dependence: A Tale of Consilience, 79 PHIL. ScI. 942, 942-51 (2012).

103 See Icard et al., supra note 79, at 86-89.

104 Formalizing this, we can write $P(C=0)$ for the probability of considering possibilities in which $C$ does not occur and $P(C=1)$ for the probability of considering possibilities in which $C$ does occur. We then write $P^{v} C=0(O=0)$ for the probability of taking $C$ to be necessary for the outcome each time one considers the question and $P^{\sigma} C=1(O=1)$ for the probability of taking $C$ to be sufficient for the outcome each time one considers the question. The causal strength measure can now be written $P(C=0)^{*} P^{{ }^{v}} C=0(O=0)+P(C=1)^{*} P^{\sigma^{\sigma}} C=1(O=1)$. See Icard et al., supra note 79 , at 86.

105 See Icard et al., supra note 79, at 81-82. 
serious revision as additional empirical results come in. Still, as we will see in a moment, this model has led to progress in the study of these phenomena that bears directly on the question we face here.

F. Normality and Disjunction

Although the model was originally developed to predict and explain three patterns that had already been observed in prior research, it also predicts a new finding that had not yet been observed. Specifically, the model predicts an effect of normality in disjunctive cases that actually goes in exactly the opposite direction of the one found in conjunctive cases.

In conjunctive cases, studies consistently show that abnormal factors are regarded as especially causal. ${ }^{106}$ However, it can be shown that the formal model predicts an effect in the opposite direction for disjunctive cases. In other words, in disjunctive cases, the model predicts that the abnormal factors should be regarded as less causal.

Studies have shown precisely that. For example, one study used the following example:

Suzy and Billy are working on a project that is very important for our nation's security. The boss tells Suzy: "Be sure that you are here at exactly 9 a.m. It is absolutely essential that you arrive at that time." Then he tells Billy: "Be sure that you do not come in at all tomorrow morning. It is absolutely essential that you do not appear at that time."

Both Billy and Suzy arrive at 9 a.m.

As it happens, there was a motion detector installed in the room where they arrived. The motion detector was set up to be triggered if at least one person appeared in the room. So the motion detector went off. 107

Participants were randomly assigned to receive either this version of the case or a version in which Billy's action of arriving at 9 a.m. was completely in accordance with the rules. Strikingly, Billy was actually regarded as less causal when he violated the norm than when he conformed to the norm. ${ }^{108}$

\footnotetext{
106 See id.

107 See id. at 87 tbl.3 (emphasis in original).

108 See id. at 87. In the time since that result was published, the effect has also been observed in a number of further studies. E.g., Gerstenberg \& Icard, supra note 94, at 600;
} 
It is hard to see how one could even begin to explain this result on the blame-based account. Why would our interest in blaming agents for their wrongdoing lead us in disjunctive cases to regard those agents who do wrong as less causal? By contrast, the result is exactly what would be predicted by the formal implementation of the normality-based account. Thus, this result provides even more reason to adopt the normality-based account rather than the blame-based account.

\section{G. Summary and Implications for Proximate Cause}

In this Part, we looked in detail at the patterns in people's ordinary causal judgments. On one hand, we find that moral considerations play a role in these judgments, but on the other, we find that this role is not best understood in terms of justifying blame or punishment. These findings open up a new possibility in our understanding of proximate cause judgments in the law. It is at least possible that moral considerations play a role in these judgments and that this role is explained by the role of moral considerations in people's ordinary concept of causation.

To assess this possibility, we will need to look more closely at the precise role of moral considerations in legal judgments of proximate cause and ask whether the patterns observed in these judgments correspond to the patterns observed in people's ordinary causal judgments. But first, we should note an obvious difficulty. The model we have presented cannot be mapped in any straightforward way onto legal judgments. It presents ordinary causal judgments as graded judgments about the degree to which an outcome was caused by the agent and the degree to which it was caused by the alternative factor. But legal judgments of proximate cause are not graded, but dichotomous: either an event is the proximate cause of harm or it isn't. There is no in-between. ${ }^{109}$

To address this difficulty, we need to introduce some terminology that makes it easier to explore the relevance of ordinary judgments for legal questions. The goal is to capture the intuition that facts about the normality of the agent's action and of the

Henne et al., supra note 94, at 160-61 (showing that omissions are regarded as more causal than actions in disjunctive cases); Justin Sytsma, The Effects of Single Versus Joint Evaluations on Causal Attributions 25 (2019) (unpublished manuscript) (showing that the effect does arise, but can be found only when participants are not asked about both potential causes).

109 Dichotomous does not imply exclusivity. Two events can both be proximate causes of the same result. 
alternative causal factor can make the case that the alternative causal factor "beats out" the agent, rendering the agent no longer causal in the way she otherwise would have been. We will say in such cases that the alternative causal factor "supersedes" the agent. ${ }^{110}$

We can characterize the ordinary notion of cause in a dichotomous fashion by using the concept of supersession. Roughly speaking, we can say that event $E$ is the ordinary cause of harm $H$ if $E$ supersedes all other alternative causal factors. Since supersession is a dichotomous notion, this notion of cause is dichotomous as well.

Because supersession will play a key role in our attempt to bridge ordinary causal judgments with legal judgments, we should be more precise about it. In particular, we need to distinguish between two ways of defining supersession. One approach is essentially comparative. We might say that the alternative supersedes the agent when facts about the normality or abnormality of the alternative make it the case that it is regarded as more causal than the agent. We refer to this as "weak supersession," and it can be defined as follows:

The alternative weakly supersedes the agent if and only if the alternative is regarded as more causal than the agent, but the alternative would not have been regarded as more causal than the agent if the alternative had been judged to be exactly as normal as the agent's action.

A second approach involves something that is not merely comparative. We might say that the alternative supersedes the agent, when facts about the normality or abnormality of the alternative make it the case that the agent is herself regarded as less causal than she otherwise would have been. We refer to this as "strong supersession," and it can be defined as follows:

The alternative strongly supersedes the agent if and only if the alternative weakly supersedes the agent, and the agent is regarded as less causal than it would have been if the alternative had been judged to be exactly as normal as the agent's action.

The formal model presented above makes specific predictions about when each of these criteria will be satisfied. We now consider these specific predictions. In conjunctive cases, the model

110 See generally Kominsky et al., supra note 89. 
predicts that any time the alternative weakly supersedes, it also strongly supersedes. In other words, at a conceptual level, we can draw a distinction between a criterion based on weak supersession and a criterion based on strong supersession, but at an empirical level, the model says that this distinction will never make any difference in conjunctive cases. In all conjunctive cases, we should arrive at the same conclusion regardless of which criterion we use.

Moreover, the model makes a very simple prediction about when the alternative supersedes. In conjunctive cases, the model says that the alternative cause should (both weakly and strongly) supersede if and only if the alternative is more abnormal than the agent's action.

In conjunctive cases, then, we can define a dichotomous notion of cause either in terms of weak or strong supersession. For all events $E$ in causal structure $S$ leading to harm $H, E$ is the cause of $H$ if $E$ weakly or strongly supersedes all alternative causal factors in $S$.

A similar strategy for disjunctive cases, however, is more complicated. In disjunctive cases, the model predicts that an alternative causal factor might weakly supersede without strongly superseding. More specifically, the alternative should never strongly supersede, but it should weakly supersede whenever the alternative is more normal than the agent's action.

Since weak and strong supersession come apart in disjunctive cases, we have two ways of defining a dichotomous notion of cause in these situations. We might say that in disjunctive cases, event $E$ is the cause of harm $H$ if $E$ weakly supersedes all alternative factors in causal structure $S$. Or we can say that $E$ is the cause of $H$ if $E$ strongly supersedes all alternative factors.

The right formula for a dichotomous notion of cause in disjunctive cases depends on which notion of supersession is closer to our ordinary notion of cause. We will not take a stand on this issue, however. For as we see in Part VI, both notions of supersession are at play in the case law.

\section{REALISM AND FORMALISM REVISITED}

The question how to understand proximate causation is a legal question (i.e., a question about how to understand a type of judgment that is made by judges or juries in the context of distinctively legal proceedings). Still, it has long been recognized that we can gain some insight into this legal question by looking 
at the kinds of judgments people make in more ordinary, nonlegal contexts. Within the traditional debate, this core methodological approach was common ground between the formalists and realists. Formalists argued that even outside of any legal context, people have an ordinary concept of causation that is in some way independent of morality. ${ }^{111}$ They then suggested that this very same concept plays a key role in legal decision-making. By contrast, realists argued that even outside of any legal context, people generally try to ensure that agents are only blamed or punished for an outcome when blame or punishment would be just or appropriate. ${ }^{112}$ They then suggested that this very same tendency drives legal judgments of proximate cause: judges try to ascribe proximate cause in such a way that the defendant is only held liable for an outcome when doing so would be just or appropriate.

As we have seen, research in cognitive science has provided us with important new data about people's ordinary causal judgment that was not available at the time of the traditional debate about proximate causation. ${ }^{113}$ People's ordinary causal judgments do not appear to be independent of moral considerations. Instead, moral considerations appear to play an important role in the way people determine whether an agent's action counts as the cause of an outcome. However, the moral judgment that plays this role does not appear to be a judgment about whether a given agent should be blamed for the outcome. It appears instead to be a judgment about the degree to which the agent violated certain norms. Thus, in cases in which people think that the agent did violate norms but should not be blamed for the outcome, people's causal judgments will tend to come apart from their judgments about whether the agent should be blamed. More strikingly, the impact of norm violation shows various surprising patterns (e.g., in disjunctive cases) that are quite different from the patterns observed for blame judgments. ${ }^{114}$

In light of these findings, it may be helpful to revisit the realist and formalist approaches to proximate causation. Each of these approaches predicts that legal judgments of proximate cause should depart in certain ways from the patterns cognitive science research has observed for people's ordinary judgments of causation. We focus now on specific types of situations. For each

\footnotetext{
111 See supra text accompanying note 50.

112 See supra text accompanying notes 36-38.

113 See supra Part III.A-B.

114 See supra text accompanying notes 90-92.
} 
such situation, our question will be whether the predictions generated by realism and formalism fit the actual patterns of the courts' decisions.

\section{A. Legal Realism}

According to received wisdom, legal realism has an easy time explaining the proximate causation case law. Judges attribute proximate causation in accordance with their moral judgments because, on the realist construal, judgments of proximate causation are moral judgments. To judge that $X$ 's action proximately caused $Y^{\prime}$ s harm is simply to judge that $X$ is responsible for $Y^{\prime} \mathrm{s}$ harm.

The evidence we have been reviewing thus far does not bear directly on claims about legal judgments of proximate cause, but it does suggest that ordinary causal judgments do not work in this way. The moral judgment that influences a person's ordinary causal judgment does not appear to be a moral judgment about whether the agent should be held responsible for the outcome. Rather, it appears to be a judgment about whether the agent's action itself violated a norm. This point comes out especially clearly in the Bartlett bookends study. ${ }^{115}$ In that study, participants received either a case in which the agent violated a norm or case in which the agent did not violate a norm. Either way, however, the outcome was something completely innocuous (having a paired set of bookends). If we focus on judgments about whether an agent is morally responsible for the outcome, one might therefore expect to find no effect at all of norm violation. Whether a theft was committed may affect whether the thief bears responsible for returning it, but not whether he is liable for the couple having a paired set of bookends. After all, no one is liable for the couple having a paired set of bookends. Because liability does not arise, one might predict that causal attributions would not be affected by whether a wrong has been committed. But that is not the actual result. Instead, norm violations seem to impact attributions of causation for all outcomes, even outcomes that are not themselves bad.

These findings turn the traditional dialectic on its head. It was usually assumed that legal realists needed to show that judges behave like ordinary people. The assumption was that ordinary people would be guided by a desire to justify blame or by

115 See supra text accompanying note 88. 
policy concerns, rather than by some complex criteria for causation. Legal realists then aimed to show that judges are, at least in this respect, like ordinary people. In light of recent empirical findings, however, it seems that we should adopt the opposite perspective. Existing empirical findings suggest that people's ordinary causal judgments are not simply guided by a desire to justify blame or by policy concerns, but instead are governed by quite complex criteria (e.g., reflecting judgments of norm violation judgment, not showing supersession in cases of overdetermination). ${ }^{116}$ For legal realists to vindicate their traditional position, they would have to show that legal judgments of proximate cause actually depart from ordinary judgments in these respects.

Of course, examples like the Bartlett Bookends study will never actually reach the courts. If the outcome is not regarded as bad, there is no legal significance to the question of whether a given agent was the cause of it. We will, therefore, never know how judges would determine which agent is the proximate cause in such a case. However, we can determine whether legal judgments depart from ordinary causal judgments by looking at cases of two other types.

First, we can look at cases in which the outcome is bad but there are strong policy reasons not to hold the defendant liable. Consider cases of intrafamily tort immunity. In many states, members of an immediate family cannot recover against each other for negligence. ${ }^{117}$ A husband who drives drunk, for example, and negligently runs over his wife is immune from tort liability. On the theory we have been developing here, this immunity should have no impact on judgments of proximate cause. The husband might not be liable, but he will still be judged to have violated a norm, and that is the only normative judgment relevant here. By contrast, on the realist interpretation, the relevant normative judgment is the judgment as to whether the husband should be held legally responsible for the damage. If proximate cause is indeed "responsible cause," as in Prosser and Keeton on the Law of Torts"118 ("Prosser and Keeton"), then because there are policy reasons for not holding the husband liable, his driving should not be regarded as the proximate cause. But this is absurd:

116 See supra Part III.G.

117 See BARRY A. LiNDAHL, 4 MOdern TORT LAW: LIABILITY AND Litigation $\S \S 28: 3$, 28:47 (2d ed. 2020).

118 KEETON ET AL., supra note 16, at 273. 
the husband's drunk driving obviously was the proximate cause of his wife's injuries.

The same problem exists in cases of sovereign immunity, diplomatic immunity, contributory negligence, expiration of the statute of limitations, etc. In these situations, defendants will not be legally responsible for the harm they proximately caused. On the realist view, however, the defendants haven't proximately caused any harm because, as a matter of policy, they are immune from liability. Not only is this a mistaken interpretation of the law, it is a poor prediction of judicial behavior. No judge would claim that immunity negates causation.

Legal realists might respond by claiming that we have misconstrued their position. Charitably interpreted, realists are not conflating judgments of proximate causation with judgments of responsibility. Rather than advancing a semantic thesis, they are stating a functional one. On this functional interpretation, the proper way to understand the concept of proximate causation is to examine its function in judicial rhetoric. Its role, according to the realists, is to justify results in hard cases. The doctrine gives judges something to say when they lack the ability or desire to state explicitly the policy reasons for their conclusions. To use Professor Green's analogy, proximate causation functions as "a joker in the game of poker." 119

On this interpretation, immunity doctrines pose no problems for the realist. In intrafamily tort cases, for example, the reason why the defendant is not held responsible for the harm negligently caused is simple and easily given, namely, the parties are family members. Not being a hard case, there is no need to resort to the doctrine of proximate causation. A judge need not deny that the husband's drunk driving was the proximate cause of the wife's injuries because he can deny recovery simply by citing the doctrine of intrafamily tort immunity and showing that it applies in this case.

Unfortunately, this functional interpretation lacks plausibility. One has to wonder why judges need the doctrine of proximate causation to justify tough decisions when they already have the doctrine of duty to do that work. Return to Henningsen. ${ }^{120}$ If the court wanted to hide its normative theorizing or found it difficult to justify its result, it could have simply used the language of duty

119 Green, supra note 9, at 612.

120 See supra text accompanying notes $1-8$. 
to accomplish that task. It could have framed the issue as whether the gun dealer had a duty to protect the infant even after the mother intervened or whether the duty did not extend that far. The fact that the court did not do so is mysterious on the functional interpretation. Indeed, the realist position renders it difficult to see why proximate causation cases exist at all. As mentioned earlier, the Third Restatement eliminated the doctrine of proximate (or legal) cause. ${ }^{121}$

Thus far, we have considered cases in which there is legal causation but no legal responsibility. We can also consider cases in which there is moral responsibility but no legal causation. These cases would also pose a problem for the realist for legal judgments of causation are supposed to track moral judgments of responsibility.

To see this, begin with standard cases of duplicative overdetermination, what we have been calling disjunctive cases. The usual legal rule is that when two independent, causally sufficient events occur simultaneously, each can be a proximate cause of a subsequent harm. ${ }^{122}$ Thus, when two separate fires join up and burn down a field, each fire is a proximate cause of the field's destruction. This is so despite the fact that neither fire is a but-for cause of the harm. Even if one fire had not been started, the field would still have been burned down.

Realists seem to have a good explanation for this result. Despite the lack of but-for causation, those who wrongly started the fires should nevertheless be held responsible for their actions. The fact that the law accords proximate causation to both disjuncts, therefore, is a plus for realists.

Unfortunately, there is a line of overdetermination cases that realists cannot explain. Several courts have held that when one of the independent, causally sufficient events is a normal, natural event but the other is a wrongful action, the normal event supersedes the wrongful action. In Cook v. Minneapolis, St. Paul \& Sault Saint Marie Railway Co., ${ }^{123}$ for example, the court held that when two fires simultaneously burn down a building, if one fire was precipitated by a natural event, it will supersede the other

\footnotetext{
121 See supra text accompanying note 49.

122 See RESTATEMENT (THIRD) OF TORTS $\S 27 \mathrm{cmt}$. a (AM. L. INST. 2010) (describing the doctrine of multiple sufficient causes).

12374 N.W. 561 (Wis. 1898).
} 
fire started by negligence and will be considered the cause of the damage. ${ }^{124}$

From the realist perspective, this result makes little sense. If judgments of proximate cause are supposed to track responsibility, why would the normal, natural events supersede wrongful actions? To the contrary, wrongdoers should be held responsible for their actions and hence judged to be the proximate cause.

\section{B. Formalism}

Formalism suffers from the same problems as realism. According to the formalists, legal judgments of proximate causation are the same as folk judgments of causation: they are descriptive in nature. But the results we explored in Part III suggest that folk judgments of causation are not descriptive. Rather, they are partially constituted by judgments of norm violations. In conjunctive cases, we found, the more wrongful an act is, the more it supersedes alternative factors. In disjunctive cases, the opposite is true: the less wrongful an act is, the more it supersedes alternative factors. In either case, folk judgments are not purely descriptive. They are partly normative.

In this respect, the case law follows suit. Proximate causation judgments show a telltale correlation with moral judgments: an action is more likely to be considered the proximate cause of harm the more wrong it is thought to be. Because descriptive judgments cannot rationally be determined by normative judgments, formalists cannot explain or condone the case law-which is what realists have claimed all along.

Formalists, of course, have been aware of the correlation between causal and moral judgments. Culpability, as Professor Moore has recognized, is often an "aphrodisiac to causation." 125 According to Moore, however, these cases are mistaken.126 The wrongness of an action is relevant to whether the defendant has breached a duty; it has no bearing on whether the defendant's breach caused the harm. To think otherwise is indefensible, for no plausible theory of morality or causation can attribute causal efficacy to moral properties. "[T]his view would require us to

124 See id. at 566.

125 MOORE, supra note 50, at 135.

126 See id. at 137 ("Such cases should be considered to be a kind of understandable mistake - understandable because often we cloud our judgment on one issue by our fervor on another, but a mistake because we have no need to double-count our culpability judgments."). 
think that moral qualities like culpability can also causally contribute ... to earthquakes and train wrecks." 127

Formalism, therefore, cannot be faulted for its inability to justify the correlation of causal with moral judgments. To the contrary, any theory that vindicates judicial behavior in such cases must itself be rejected. "If one finds the needed metaphysics to be too implausible to be even seriously considered, then one should reject those cases (and the doctrines they announce) that would impose this demand on legal causation." 128

This response, unfortunately, misses the mark. To see this, recall the distinction introduced earlier between causal contribution and causal selection. ${ }^{129}$ As we argued, a theory of proximate causation is a theory of causal selection-it selects which of the indefinitely many events that causally contributes to the production of some harm counts as the cause. Existing theories in cognitive science suggest that morality is a determinant of causal selection. They do not make the absurd claim that the moral properties of an action causally contribute to the occurrence of effects; rather, they maintain that the degree to which an action counts as the cause of the subsequent outcome depends in part on the degree to which it violates norms.

Professors H.L.A. Hart and A.M. Honoré offered a different response. Rather than run away from these cases, they attempted to explain these decisions in a formalist fashion. To do so, Hart and Honoré invoked two principles that they claimed govern causation both inside and outside the law. The first principle is their famous thesis that voluntary human acts are intervening events that break causal chains. ${ }^{130}$ On Hart and Honoré's interpretation, our common-sense conceptions of agency and causation treat voluntary actions as uncaused causes. Because these events are the product of a free, uncaused will, they necessarily sever the causal connection between themselves and preceding events. Thus, if I toss a cigarette in the bramble and before the fire peters out someone pours gasoline on the smoldering site, the latter voluntary action breaks the causal chain and I am no longer the proximate cause of whatever fire and damage ensues.

The second principle adduced by Hart and Honoré is that actions that are so abnormal as to be contrary to human nature

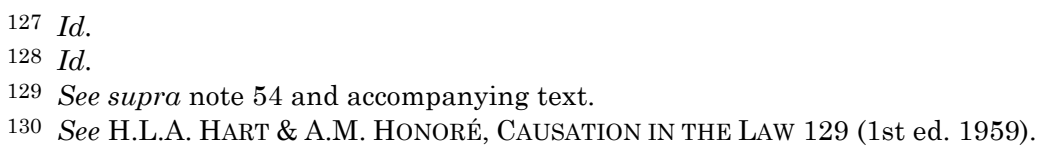


count as intervening events which break causal chains. ${ }^{131}$ Such actions are akin to animal behavior. Just as unforeseeable animal behaviors sever causal connections, highly abnormal human actions intervene and break causal chains.

Hart and Honoré used the first principle to show why negligent actions do not break causal chains. Consider Thompson $v$. $F_{0 x},{ }^{132}$ in which a driver negligently ran over the plaintiff with his car, causing a hip fracture. ${ }^{133}$ When the plaintiff was taken to the hospital for treatment, his doctor allegedly "carelessly and improperly treated the fracture," causing pain and requiring further surgeries. ${ }^{134}$

The court held that the doctor's negligence was not a superseding cause. ${ }^{135}$ On Hart and Honoré's view, the doctor's malpractice did not intervene between the harm and the driver's previous negligence because the doctor's actions were not voluntary: "Every merely negligent act is non-voluntary in our sense, since by hypothesis the actor did not intend the consequence." ${ }^{136} \mathrm{Be}-$ cause the doctor did not intend to harm the patient, his malpractice was not voluntary and hence did not supersede the original negligence.

Having explained why negligence does not break causal chains, Hart and Honoré proceeded to explain why gross negligence does. Consider Purchase v. Seelye, ${ }^{137}$ in which a railroad employee suffered a hernia on the right side of his groin as the result of the railroad's alleged negligence. When the employee was taken to the hospital, the surgeon confused him with another hernia patient and operated on the left side instead. 138 The court held that the doctor's gross negligence intervened between the railroad's negligence and the employee's harm. ${ }^{139}$ According to Hart and Honoré, the doctor's actions were superseding events because gross negligence is highly abnormal and highly abnormal actions, on the second principle, break causal chains. ${ }^{140}$

\footnotetext{
131 See id. at 166.

132192 A. 107 (Pa. 1937)

133 See id. at 108.

134 Id.

135 See id. at 109.

136 HART \& HONORÉ, supra note 130, at 131.

137121 N.E. 413 (Mass. 1918).

138 Id. at 413 .

139 Id. at 414

140 HART \& HONORÉ, supra note 130, at 170.
} 
Hart and Honoré's response, however, is ad hoc. Only in a very forced sense is negligent action "non-voluntary." In Thompson, the doctor wasn't sleepwalking; his hands were not being manipulated by another doctor; nor was he being coerced by some thug. He acted freely, if incompetently. Moreover, as Moore has pointed out, treating negligent action as nonvoluntary is at odds with the libertarian justification that Hart and Honoré adduce for their first principle. ${ }^{141}$ If voluntary actions break causal chains because they are uncaused causes, how can negligent actions not break causal chains as well? On a libertarian framework, negligent acts are just as uncaused as nonnegligent ones. Indeed, the doctor is morally responsible for his malpractice precisely because he caused his negligent actions.

Hart and Honoré's use of their second principle to explain cases like Purchase is also highly artificial. It is implausible to claim that gross malpractice is so abnormal as to be contrary to human nature and akin to animal behavior. ${ }^{142}$ Serious stupidity is, alas, all too human.

It should come as no surprise that Hart and Honoré's explanation of the case law is stilted. Consider the difficult challenge they faced. Given their formalist commitments, Hart and Honoré could not explain the difference between cases of negligence and gross negligence in the most obvious manner, namely, by pointing out that gross negligence is morally worse than negligence. Because they were precluded from appealing to moral distinctions, Hart and Honoré were forced to devise some descriptive difference to account for the cases. Their characterization of negligence as "nonvoluntary" and gross negligence as "contrary to human nature" is surely artificial, but it is doubtful that there is a better way to hammer the square descriptive pegs into the round moral holes. ${ }^{143}$

\footnotetext{
141 See Moore, supra note 50, at 237-40.

142 Treating gross negligence as highly abnormal is not only artificial; in most instances, it would render the first principle redundant. If gross negligence is highly abnormal, then intentional wrongdoing must be even more so. The doctor who stabs his patient because he is love with the patient's wife would be the proximate cause of the patient's death not only because the stabbing is a voluntary act; it would also break any previous causal chain because it is highly abnormal.

143 For further criticism of Hart and Honoré's account of proximate causation, see Stapleton, supra note 51, at 461-65.
} 


\section{FOLK JUDGMENTS AND LEGAL JUDGMENTS}

Now that all of the pieces are in place, we can introduce our own positive proposal. We suggest that legal judgments of proximate cause are based, at least for the most part, on people's ordinary concept of causation. Roughly speaking, for any causal factor $C$ of the causal structure $S$ leading to harm $H, C$ is the legal cause of $H$ if and only if $C$ is the ordinary cause of $H$.

As we argued in Part III, this strategy of tying legal judgments to ordinary judgments of causation will work only if we use a dichotomous notion of cause. To do so, we rendered the ordinary notion of cause in terms of supersession. We suggested that $C$ is the cause of $H$ if $C$ supersedes all other events of $S$. Putting these two ideas together, we get: $C$ is the legal cause of $H$ if $C$ supersedes all other elements of $S$.

Finally, we must distinguish between conjunctive and disjunctive cases. Recall that in conjunctive cases, $C$ (weakly and strongly) supersedes all other alternative causal factors in $S$ if and only if $C$ is more abnormal than all other events in $S .{ }^{144}$ Thus, in conjunctive cases, we get the simple formula: $C$ is the legal cause of $H$ if $C$ is more abnormal that all other elements of $S$.

As noted at the end of Part III, disjunctive cases are more complicated because of the distinction between weak and strong supersession. In disjunctive cases the more normal an event is, the more likely it will weakly, but not strongly, supersede all other events. Thus, whether the normality of an event makes it more likely to be the cause of harm in disjunctive cases depends on whether the ordinary notion of cause tracks weak, but not strong, supersession.

If the ordinary notion of cause tracks weak supersession, then in disjunctive cases, $C$ is the legal cause of $H$ only if $C$ is more normal than all other elements of $S$. But if the ordinary notion of cause tracks strong supersession, then the greater normality of an event does not make it more likely to be the legal cause of $H$.

$$
* * *
$$

Before we go on to test these proposals against the case law, we should pause to consider a puzzle. We claim that legal judgments of proximate cause are based on judgments of normality. But why does the law care about normality?

144 See supra Part III.G. 
It makes sense for the law to care about normality, we suggest, because normality gives us a sense of which possibilities a reasonable agent would have taken account of before acting. Consider the position of a defendant before she decided to act. Which decision she ought to take depends on what other agents will do, as well as on various other background conditions. But she can't possibly consider all possible ways these other things can be. Nor should she have to. It's not her responsibility to consider every possibility and take precautions against all conceivable harms. She is not under an absolute duty to safeguard the physical security of everyone else.

Our suggestion is that a reasonable agent would consider the normal ways things could be. First consider statistical norms. The more likely something is to happen, the more important it is for the defendant to consider it. If she contemplates throwing a burning cigarette on the ground, she should anticipate the normal possibilities that might follow upon such an action. If a storm is approaching, will the wind whip up to spread the fire? If near a gas station, will fumes waft by to cause an explosion? If there has been a drought, are the leaves on the ground very dry and liable to burst into flames? These are all scenarios that a reasonable person would consider-not only because they are harmful, but normal in the circumstances. It would be unreasonable for the defendant to worry about an oil geyser erupting from the ground or an airplane dropping tinder from above. While they are logical possibilities, they are so unlikely that a reasonable person need not take them into account or take precautions against them. Requiring people to take such precautions would be unfair-it would impose crushing burdens on everyone to protect the security of everyone else.

This same suggestion also applies to prescriptive norms. Other things being equal, the greater the wrong a person might commit, the less others need to take this possibility into account. If a defendant is driving, she ought to contemplate the possibility that the driver in front of her might make a mistake. The driver might accidentally jam on the breaks. Or that driver might negligently ram into the car in front of her. The defendant needs to consider these possibilities because human beings are fallible. She ought to give herself a safe driving distance to avoid an accident if the driver in front mistakenly stops.

But there are limits to the defendant's responsibility to safeguard others from wrongdoing. The defendant may be driving 
through a high-crime area, but is not under a duty to bulletproof her car. Nor does she have to give extra room to the vehicle in front just in case the passengers open fire on a rival gang. These behaviors are too abnormal-not in the statistical sense we previously considered, but in the moral sense. It is unfair to require people to take precautions against the highly immoral actions of others. To do so would be to shift the cost of highly abnormal behavior from wrongdoers to innocent bystanders.

Thus the notion of normality-which seems to play such a key role in people's ordinary causal judgments-seems to be tracking something of real normative significance. ${ }^{145}$ Indeed, we (tentatively) suggest in the next Part that judgments about what a reasonable agent ought to take into account might actually be impacting representations of normality that play a role in some causal judgments.

\section{TESTING THE MODEL}

The key test of this proposal is the degree to which it fits the patterns in existing case law. As we have seen, findings from cognitive science point to some surprising patterns in people's ordinary causal judgments. If we are right in suggesting that legal judgments of proximate cause are based on these ordinary causal judgments, one should expect to find those same surprising patterns in the former.

Of course, there is no real hope that an account like ours will explain absolutely everything about the patterns observed in legal judgments. No matter how much it successfully explains, there will inevitably be other factors that play at least some role, and a full account of the patterns in proximate cause judgments will have to take these other factors into account as well. Most importantly for present purposes, there may be certain unusual cases in which a straightforward application of the ordinary concept of causation would lead to results that are unacceptable from a policy perspective. In such cases, it may happen that the courts override their criteria for proximate cause judgment and make a special exception for policy reasons.

145 According to the Third Restatement, "[a]n actor's liability is limited to those harms that result from the risks that made the actor's conduct tortious." RESTATEMENT (THIRD) OF TORTS $\S 29$ (AM. L. INST. 2010). Since the risks that make an actor's conduct tortious are those that a reasonable person would consider and take precautions against, our normality proposal tracks the recommendation of the Third Restatement. 
Consider, for example, the old "first building" rule adopted by New York, in which a defendant is only responsible for the first building burned down by a negligently started fire, but not for other structures that may have subsequently caught fire. ${ }^{146}$ Clearly, the limitation on causation to the first building was motivated by policy considerations. New York law at the time regarded the imputation of the cost of the entire town to one person to be too great a burden. Any acceptable theory should allow for these situations where policy is the dog that is wagging the proximate cause tail.

Note, however, that the suggestion we are making here is significantly different from the traditional realist view. On the traditional realist view, all proximate cause judgments are basically matters of policy, and attempts to explain such judgments in terms of the criteria governing the concept of causation are nothing more than window dressing. By contrast, on the present proposal, almost all proximate cause judgments are really applications of the criteria governing the ordinary concept of causation. Then there are certain rare cases in which these criteria would lead to absurd or unacceptable results, and in those exceptional cases, the courts do something different from what they usually do: they override the usual criteria and make a judgment based on policy. Thus, the prediction of the present proposal is not that absolutely all cases will be decided in accordance with the ordinary concept of causation. It is rather that almost all cases will be decided in this way, and that the only exceptions will be cases in which a straightforward application of the criteria governing the ordinary concept would lead to unacceptable results.

It bears emphasizing that in these exceptional cases, courts are almost always explicit about the fact that they are making a decision based on policy considerations. When the doctrine of proximate causation is merely window dressing, courts say so. In justifying the first building rule, for example, the court in Ryan $v$. N.Y. Central Railroad Co., ${ }^{147}$ wrote:

To hold that the owner must not only meet his own loss by fire, but that he must guaranty the security of his neighbors on both sides, and to an unlimited extent, would be to create a liability which would be the destruction of all civilized society. ... To neglect such precaution, and to call upon his

146 KEETON ET AL., supra note 16, § 44, at 282.

14735 N.Y. 210 (1866). 
neighbor, on whose premises a fire originated, to indemnify him instead, would be to award a punishment quite beyond the offense committed. ${ }^{148}$

$$
* * *
$$

To assess our proposal, we turn to the case law. Unfortunately, we cannot test the adequacy of our model against current legal doctrine. Given the literally thousands of opinions in state and federal jurisdictions that are relevant to determining the doctrine of proximate causation, a complete analysis of the case law is beyond the scope of this Article.

To render the discussion tractable, we adopt three major restrictions. First, we focus on proximate cause in torts, in particular the tort of negligence. Second, we explore the cases and analysis set out in the latest edition of Prosser and Keeton on the Law of Torts. Prosser and Keeton is not only the classic treatise on tort law, but it adopts an avowedly realist methodology. Using a highly respected hornbook that adopts a different approach from our own minimizes the danger of cherry picking, i.e., choosing the cases we discuss to fit our own model.

Third, we limit our discussion of the case law to two doctrines. For conjunctive cases, we focus on intervening causation. In cases of intervening causation, the defendant's causally insufficient act combines with another causally insufficient event occurring later in time to cause harm. The question in these cases is whether the latter event breaks the causal chain and supersedes the defendant's earlier action as proximate cause. Thus, the Henningsen case is one of intervening causation: the gun owner causally contributed to the shooting of Henningsen by selling the gun to a thirteenyear-old, but the mother's ineffective hiding contributed as well. ${ }^{149}$

In our model, one event supersedes another in conjunctive cases just when the former is more abnormal than the latter. Our model will fit the case law, then, if the cases hold that (1) more abnormal events supersede and (2) equally normal events do not supersede. Thus, Henningsen fits our model because the mother's ineffective hiding of the gun was (roughly) as normal as the shop owner's sale of the gun to a minor, and hence the mother's actions do not supersede.

$148 I d$. at $216-17$.

149 See Henningsen, 230 N.Y.S. at 315-17. 
In disjunctive cases, we cannot examine instances of intervening causation because there are none. If one sufficient cause occurs before another (e.g., one fire burns down a building before another fire arrives), the first sufficient cause is the cause of the event. We therefore consider cases of so-called concurrent causation (i.e., where two causally sufficient events co-occur, as when two intentionally created fires burn down a building simultaneously).

Testing our hypothesis in disjunctive cases, however, is more complex than the conjunctive cases because strong and weak supersession come apart in these cases. Ignoring that complication for the moment, we will say that our model fits the case law if the cases hold that (1) less abnormal events supersede and (2) equally normal events do not supersede. The law governing simultaneous arson, for example, fits our model because both are equally abnormal and hence do not supersede each other, which is precisely what the law dictates. (Whether more normal intervening events legally supersede less normal events depends on whether weak supersession counts for the purposes of ordinary causation-more on this in Part III.)

\section{A. Intervening Causation}

Prosser and Keeton sets out the fundamental principle that it claims governs all proximate cause cases: foreseeable events do not supersede. "Foreseeable intervening forces are within the scope of the original risk. ... The courts are quite generally agreed that intervening causes which fall fairly in this category will not supersede the defendant's responsibility." ${ }^{50}$ When a foreseeable cause occurs, it does not break the causal chain between the original wrongful act and the later damage. The original wrongful act remains the proximate cause of the harm.

In its discussion of intervening causation, Prosser and Keeton attempts to explain why cases come out the way they do-why some intervening events supersede, while others do not-purely in terms of foreseeability. We will follow Prosser and Keeton's order of presentation, analyzing cases in the order that they raise them.

\footnotetext{
150 KEETON ET AL., supra note $16, \S 44$, at 303-04.
} 
1. Negligence.

Prosser and Keeton begins by identifying two kinds of foreseeable events that do not supersede: natural events and negligent actions.151 Foreseeable natural events include "usual wind or rain," "that animals which are loose will wander into danger," and "that mosquitos will breed in a swamp." ${ }_{152}$ None of these events supersede the defendant's liability. If the defendant negligently starts a fire and a normal wind spreads it, the intervening wind does not supersede the negligent act. The defendant is still the proximate cause of the fire damage.

The second set of events that intervene but do not supersede are negligent actions. These include driving into a car parked on a highway without its lights on or negligently throwing a match on spilt gasoline. ${ }^{153}$ These acts do not break causal chains: if the defendant parked the darkened car or spilled the gasoline, she remains the proximate cause of the resulting harm regardless of the intervening negligence. Henningsen, too, falls into the same pattern: the mother's negligence in hiding her son's air rifle was foreseeable and hence does not supersede the gun owner's original sale to the minor.

According to Prosser and Keeton, negligent actions do not break causal chains because they are foreseeable. ${ }^{154}$ They fully recognize the precariousness of their claim. Not all negligent actions seem foreseeable - in the sense of being statistically normal. Consider Matthews $v$. Porter, ${ }^{155}$ cited by Prosser and Keeton. ${ }^{156}$ Grover Porter drove negligently and collided with a car on a highway. Jacqueline Matthews, a bystander, stopped at the accident scene to help Porter's wife who was injured. Meanwhile, two cars slid sideways as the result of another instance of negligent driving further up the highway. One of those cars crushed Matthews. The court held that the second intervening negligence-the second accident leading to cars sliding sideways down the highwaydid not supersede the Porter's original act of negligence. ${ }^{157}$

151 It also briefly discusses a third category: foreseeable criminal intervening acts. See infra Part V.A.5.

152 KeETON ET AL., supra note $16, \S 44$, at 304.

153 Id. $\S 44$, at 305.

154 See id. $\$ 44$, at 304 .

155124 S.E.2d 321 (S.C. 1962).

156 KEETON ET AL., supra note 16, § 44, at 306 n.50.

157 See Matthews, 124 S.E.2d at 327. 
To deal with the implausibility of this statistical claim, Prosser and Keeton distinguishes between two different senses of foreseeability. The first sense of foreseeability refers to what would have been "contemplated by any reasonable person in the place of the defendant at the time of the conduct."158 A negligent driver should foresee, in this sense, that his driving may cause an accident. The second is a broader notion, one that has "undergone [a] process of dilution and attenuation," and has to do not with what the party should literally "have in mind," but with what is "foreseeable in the sense that any event which is not abnormal may reasonably be expected to occur now and then, and would be recognized as not highly unlikely if it did suggest itself to the actor's mind." 159 Examples of the second, broadened sense of foreseeability include foreseeing that a potential accident caused by one's negligent driving will in turn cause a second, subsequent collision ${ }^{160}$ - a fact pattern similar (but not identical) to the one in Matthews.

Prosser and Keeton concedes that this broadened use of foreseeability has "traveled a long way from its original meaning," but nevertheless justifies its use by suggesting that it's merely "a pointless quibble over the meaning of a term to debate whether such normal intervening causes are to be called 'foreseeable."' 161

In our model, by contrast, foreseeability plays an important, but not exclusive, role. For natural events, foreseeability matters because foreseeable events are statistically normal. Since these intervening events are normal, they are not more abnormal than the original negligence. Thus, our model correctly predicts that the liability of the original defendant will not be superseded.

Our model, however, treats negligent actions not as foreseeable (i.e., statistically normal), but rather as morally abnormal. But since they are generally not more abnormal than the original-also negligent-act of the defendant, they do not supersede. Recall our original puzzle in Henningsen. ${ }^{162}$ There, both the gun dealer and the mother acted negligently: the dealer in illegally selling the gun to the boy, and the mother in hiding the gun where the boy could find it. But because the subsequent act of the

\footnotetext{
158 KEETON ET AL., supra note $16, \S 44$, at 306.

159 Id. $\S 44$, at 306-07.

160 See id. § 44, at 306.

161 Id. $\S 44$, at 306-07.

162 See supra text accompanying notes 7-13.
} 
mother was, though negligent, not more negligent than the original wrongdoing of the dealer, it does not break the causal chain.

Indeed, our model helps to account for this "apparent confusion." Prosser and Keeton cites cases, such as Henningsen, where parents fail to protect their children from dangerous items sold to them. Prosser and Keeton describes two versions of such a case: (1) the parents negligently failed to learn about the dangerous object, and (2) the parents learned about the object but negligently failed to hide it successfully (as in Henningsen). ${ }^{163}$ The "apparent confusion" lies in the fact that, in the first kind of case, the parental failure does not supersede and the defendant uniformly is held liable. ${ }^{164}$ But in the second kind of case, the result varies. Indeed, some such latter cases come out the other way from Henningsen: when the parents knew about the nature of the object but still failed to hide it, the failure supersedes and the original seller is absolved of liability. ${ }^{165}$

Our account can explain the difference in these cases by the margin of relative negligence involved. If the parents did not suspect the dangerous nature of the object, then their failure to hide it, though negligent, is not more norm-violating than the actions of the seller who knowingly sold a dangerous object to a child. But in the second case, the issue will come down to the particular facts in determining who, among the parties aware of the dangerous object, was more abnormal: the parent who failed to hide it or the person who sold it in the first place. In some cases, the parent's failure is deemed more abnormal than the seller and the failure supersedes. But in cases like Henningsen, when the danger of the object was arguably "so extreme that the defendant could not reasonably rely upon even the parent to protect the child," 166 the seller intuitively behaved at least as negligently as the parent, if not more so, and so their sale is not superseded by the parental negligence.

\section{Rescue.}

Prosser and Keeton next addresses the "rescue doctrine," under which efforts to save someone or something from an original wrongdoer typically do not supersede. ${ }^{167}$ As it notes, the rescue

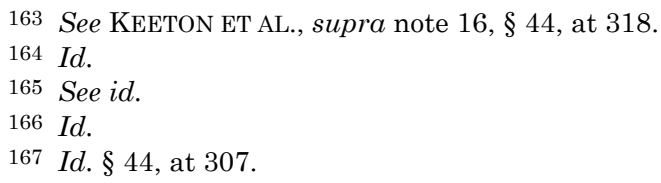


doctrine does not fit the foreseeability model: "Whether or not the rescuer is to be regarded as 'foreseeable', it has been recognized since the early case of the crowd rushing to assist the descending balloonist that the rescuer is nothing abnormal." 168

Indeed, cases of rescue are unusually severe in preserving, and even extending, the liability of the original defendant. For instance, the defendant may have an independent duty of care to protect the rescuer, even when the defendant endangers only his own safety, as in an attempted suicide. The defendant may be liable even if the rescuer harms not only themselves, but the person rescued or a third party. Most courts extend the duty of care to rescued property, even if it is the defendant's property. There have even been cases of recovery to a rescuer of a rescuer of property. ${ }^{169}$ And the original defendant may be liable even when "defensive efforts may be negligent, and so may endanger others. It is only when they are so utterly foolhardy and extraordinary that . . . they will be considered a superseding cause." 170

Our model provides an explanation for why rescue cases tend to be so broad in preserving the causal relation between the original negligent actor and the eventual harm: those who rescue a victim are generally acting laudably, and therefore the rescue is generally less morally abnormal than the original wrongdoing. Even when the rescue is itself negligent, it is still not more morally abnormal than the-also negligent-original wrongdoing, and so does not break the causal chain. Indeed, our model helps to explain why the bar for superseding negligence in rescue cases is so high: that is, why only "utterly foolhardy and extraordinary" negligence will supersede. Because a rescue is regarded as a prima facie morally laudable action, it makes sense that only a very high degree of negligence (i.e., recklessness) will render even a negligent rescue morally worse than the original defendant's wrongdoing.

\section{Medical malpractice.}

Prosser and Keeton describes a similar pattern for medical malpractice cases: negligence does not supersede, but recklessness does. ${ }^{171}$ Recall Thompson, ${ }^{172}$ in which the court held that the

\footnotetext{
168 See KEETON ET AL., supra note $16, \S 44$, at 307.

169 See id. § 44, at 308 nn.66, 68-70, 72-74 (collecting cases).

170 Id. $\S 44$, at 309.

171 See id. § 44, at 309-10.

172 See supra text accompanying notes $132-35$.
} 
doctor's negligence in treating injuries from a car accident was not a superseding cause:

Doctors, being human, are apt occasionally to lapse from prescribed standards, and the likelihood of carelessness, lack of judgment or of skill, on the part of one employed to effect a cure for a condition caused by another's act, is therefore considered in law as an incident of the original injury. ${ }^{173}$

But certain kinds of medical malpractice, including such "highly unusual varieties" as where a medical professional inflicts an intentional injury, do break the causal chain. ${ }^{174}$ For this proposition, Prosser and Keeton cites to the Second Restatement of Torts, which offers several illustrations of "extraordinary" medical malpractice superseding the original defendant's liability:

$A$ negligently inflicts serious harm on $B$. While $B$ is in a hospital under treatment, his nurse, unable to bear the sight of his intense suffering, gives him a hypodermic injection of morphine in disobedience of the surgeon's instructions and so excessive that she knows it may be lethal. $B$ dies as a result of the injection. $A$ 's negligence is not a legal cause of $B$ 's death.

$A$ negligently injures $B$ so severely as to require him to go to a hospital for treatment. While he is there, his manners annoy $C$, one of the male nurses, who, in revenge, attacks $B . A$ is not liable for the harm inflicted by $C .{ }^{175}$

Prosser and Keeton explains this difference in judicial behavior by reference to foreseeability. On its view, ordinary malpractice is foreseeable but extraordinary medical malpractice is unforeseeable. ${ }^{176}$

Our model explains this change in judicial behavior by reference to moral normality. In contrast to cases such as Thompson, in which the medical malpractice is described as "doctors[] being human," 177 the second set involves instances of extraordinary wrongdoing, going far beyond ordinary negligence. In these second set of cases, in other words, there is a significant moral asymmetry between the original defendant and the intervening

\footnotetext{
173 Id. at $108-09$.

174 KEETON ET AL., supra note $16, \S 44$, at 309.

175 RESTATEMENT (SECOND) OF TORTS $\S 457$ illus. 4-5 (AM. L. INST. 1965).

176 See KeETON ET AL., supra note 16, § 44, at 309-10.

177 Thompson, 192 A. at 108.
} 
medical practitioner: When the original defendant's behavior was merely negligent, the intervening act is either grossly negligent (as in the first example), or intentional (as in the second example). Because these intervening acts are more morally abnormal than the original negligence, our model correctly predicts that they supersede.

\section{Suicide.}

Prosser and Keeton next describes cases in which injury inflicted by a defendant leads to the victim's suicide. ${ }^{178}$ Here, the case law divides into two general categories. If the suicide is committed in a state of insanity that "prevents one from realizing the nature of one's act or controlling one's conduct," then it is typically deemed to be "a direct result" of that injury "and no intervening force at all." 179 The insane intervening suicide does not supersede and thus the original defendant is held liable.

If, on the other hand, the injured person is sane or "in full command of all faculties" and thus commits suicide as a "voluntary choice," then the case law once again divides into two categories. ${ }^{180}$ If the initial injury was inflicted through negligence, then the (sane) suicide typically supersedes the defendant's original wrongdoing. ${ }^{181}$ If, however, the initial injury was intentional, as in cases of blackmail, rape, or torture, then recovery has been allowed, even though the injured party was sane at the time of the suicide. ${ }^{182}$

Prosser and Keeton offers no explanation for this pattern of behavior, simply noting that "[s]ome difficulty has arisen" in these cases. ${ }^{183}$ Our model can help to account for these divisions in the case law. We begin by noting that suicides register as statistically abnormal. The current rate of suicide in the United States is about $0.014 \% .184$ What about its moral abnormality?

Historically, at common law, committing suicide was regarded as both morally and legally wrong. ${ }^{185}$ Throughout the

178 See KeETON ET AL., supra note 16, § 44, at 310.

179 Id. $\S 44$, at $310-11$.

180 Id. $\S 44$, at 311 .

181 Id.

182 See id. § 44, at 311 n.97.

183 KEETON ET AL., supra note $16, \S 44$, at 310.

184 Suicide Statistics, AM. FOUnd. FOR SUICIDE Prevention (Mar. 1, 2020), https://perma.cc/A8TE-E2NP.

185 Under English common law, suicide was a felony; Blackstone's Commentaries define "felonious homicide" as "killing one's self, or another man," without distinguishing 
twentieth century, the legal consequences for suicide were largely abolished or unenforced ${ }^{186}$ - suggesting that suicide was no longer regarded as being equally objectionable as other behavior that continued to be criminalized-but the act remains morally stigmatized. ${ }^{187}$

Here, however, we must distinguish between sane and insane suicides. The moral abnormality can only apply to a sane suicide. In the insane suicide, where the action is "the same as if one [] hurt oneself during unconsciousness or delirium," 188 any persisting moral stigmatization of suicide would not be expected to apply, since the act is involuntary and unconscious. In these cases, this unconscious act is not morally worse than the original negligence, and so our model predicts that it will not supersede: exactly what the case law reflects.

In cases of sane suicides, however, the situation is different. Where suicide retains its association with moral and, in certain jurisdictions, criminal wrongdoing, the deliberate and voluntary choice to kill oneself will be treated as morally more abnormal than the original negligent act-and indeed suicide tends to supersede in negligence cases. ${ }^{189}$ But in cases in which the original injury is itself criminal-such as the blackmail, rape, and torture cases that Prosser and Keeton mentions ${ }^{190}$ - one would expect that the suicide, though morally stigmatized, is less morally abnormal than these egregious wrongdoings. ${ }^{191}$ And as our model would predict, the original defendant has been held liable in such cases.

In this way, our model allows us to account not just for the difference between sane and insane suicide cases, but also for the

between suicide and murder. 2 WiLliam BlaCkstone, COMMENTARIES ON THE LAWS OF ENGLAND *188-89.

186 In the United States, suicide remained a common law crime in several states, but the associated penalties were either abolished or unenforced. See Cruzan v. Dir., Mo. Dep't of Health, 497 U.S. 261, 294 (1990) (Scalia, J., concurring); Wackwitz v. Roy, 418 S.E.2d 861, 864-65 (Va. 1992).

187 See G. Tadros \& D. Jolley, The Stigma of Suicide, 179 BRIT. J. PsYCH. 178, 178 (2001) (finding that the present "[s]tigmatisation of suicide has very deep roots in our collective thinking and judgment"). As recently as 1990, the Supreme Court rejected the notion that suicide is legitimized. See Cruzan, 497 U.S. at 280.

188 KEETON ET AL., supra note $16, \S 44$, at 311.

189 Id. $\S 44$, at 311 n.98.

190 See id. § 44, at 311 n.97 (citing Tate v. Canonica, 5 Cal Rptr. 28, 31 (Ct. App. 1960) (apparent intentional infliction of mental disturbance by blackmail); Stephenson v. State, 179 N.E. 633, 635 (Ind. 1932) (suicide by a rape and torture victim); Cauverien v. De Metz, 188 N.Y.S.2d 627, 631 (Sup. Ct. 1959) (“malicious and wilful conversion”)).

191 After all, criminal penalties for suicide have either been abolished or unenforced in the twentieth century, while acts like blackmail, rape, and torture continue to be crimes. 
difference, within the sane cases, between merely negligent and intentionally inflicted initial injuries-a difference neither Prosser and Keeton's foreseeable/unforeseeable distinction nor Hart and Honoré's voluntary/involuntary distinction is able to explain.

5. Foreseeable means.

Prosser and Keeton next describes an interesting group of cases in which the harm is foreseeable but the intervening cause is not. ${ }^{192}$ For example, suppose someone forgets to clean out the residue of an oil tank. The tank is hit by a bolt of lightning and explodes. ${ }^{193}$ Though the intervening cause is unforeseeable-a lightning strike is the ultimate unforeseeable event-it is foreseeable that an oil tank with residue will explode.

As Prosser and Keeton notes, the cases split into two groups. The first set of cases includes not only the lightning case just mentioned, but also cases involving "a ladder left standing in the street blown down by an unforeseeable wind; an obstruction in the highway with which a runaway horse collides; ... [and] a termite-riddled telephone pole thrown down by an automobile which comes up on the sidewalk." ${ }^{194}$ In each of these cases, the ultimate harm, described in general terms, is foreseeable: the dirty oil tank explodes, the ladder left in the street falls, the rickety pole collapses. What isn't foreseeable is the specific way in which the harm comes about. In these cases, the original defendant is held liable in accordance with the "well settled" rule that "if the result is foreseeable, the manner in which it is brought about need not be, and is immaterial." 195

Prosser and Keeton next considers a set of cases that nevertheless contravene this "well settled" rule: cases in which an unforeseeable cause produces a foreseeable result, but in which the original defendant's liability is nevertheless superseded. ${ }^{196}$ For instance, a defendant negligently excavates a dangerous hole in the sidewalk, but the plaintiff is deliberately pushed into it. ${ }^{197}$ Or:

\footnotetext{
192 See id. $\S 44$, at 316-18.

193 See Johnson v. Kosmos Portland Cement Co., 64 F.2d 193, 194 (6th Cir. 1933).

194 KEETON ET AL., supra note 16 , § 44, at 316-17.

195 Id. § 44, at 317 .

196 See id. $\S 44$, at $317-18$.

197 E.g., Alexander v. Town of New Castle, 17 N.E. 200, 201 (Ind. 1888).
} 
[A] chair seat is left on a balcony railing, and it is purposely thrown down, or a policeman aware of the danger of a live wire knocks it with a club against the plaintiff, or a stranger impersonating an elevator operator deliberately invites the plaintiff to step into an open shaft. ${ }^{198}$

In all of these cases, the original negligence leads to a result that is, in general terms, foreseeable, but for which the defendant is nevertheless not held liable.

Prosser and Keeton says that "[t]he difference between the two groups of cases is a matter of intangible factors not easy to express. It apparently lies in the conclusion of the courts that in the latter type of case the responsibility is shifted to the second actor." 199 To be sure, the courts conclude that, in the second kind of case, responsibility is shifted. But why do they so conclude? Prosser and Keeton continues:

Where there is a malicious or criminal act, the original actor might be free to say, even if anticipating the misconduct, that it was not the actor's concern, whereas the actor might still be responsible for inadvertence or ignorant blunders. Where the defendant would be relieved of responsibility even if the act were to be anticipated, the defendant should be no less relieved when it is unforeseeable. ${ }^{200}$

But such an answer merely shifts the question to why the defendant is relieved of responsibility in the latter group of cases, even if the result were to be anticipated, and not in the former. Prosser and Keeton offers no answer to this more basic question.

Our model, on the other hand, provides a by-now-familiar explanation for the difference between these two sets of cases. The two sets are similar in statistical abnormality, but not moral abnormality. In the first set of cases, the intervening causes are either instances of negligence (like the pole and ladder struck by passing automobiles, or the pile of lumber knocked over by a passerby) or natural events (like a lightning strike, a sudden wind, or a termite infestation). So in each of these instances, the intervening cause is either equal to or less morally abnormal than the original negligence of the defendant-as the model predicts, such intervening causes do not supersede. But in the second set

198 KeETON ET AL., supra note 16, § 44, at 317-18 (citing Cole v. German Sav. \& Loan Soc'y, 214 F. 113 (8th Cir. 1903)).

199 Id. $\S 44$, at 318 .

$200 \mathrm{Id}$. 
of cases, the intervening causes are "malicious or criminal acts" (such as shoving the plaintiff into a hole, or striking a person with a live wire), and are therefore more morally abnormal than the original defendant's negligence. In these cases, the model predicts-and the case law bears out - that the intervening cause will supersede the defendant's liability. ${ }^{201}$

Our model thus provides a uniform and consistent set of explanations for the variations of judicial behavior present in the intervening cause doctrine that Prosser and Keeton describes. Its chief explanatory notion of abnormality allows it to account for features of the case law that Prosser and Keeton's preferred tool of foreseeability is unable fully to explain.

\section{Problematic cases.}

Finally, there are two categories of cases which, in our model, require some special treatment. The first involves intervening causes that are both statistically and morally more abnormal than the original negligence and yet fail to supersede. Examples include: a hotel held liable for jewelry burgled from its negligently unlocked safe; 202 a contractor held liable for failing to maintain proper barricades, even when those barricades were wrongfully removed by a third party; ${ }^{203}$ a school held liable for the rape of a negligently unsupervised child in a school gym;204 and a railroad held liable for the rape of a passenger negligently dropped off at an unsafe location. ${ }^{205}$ Our model, however, predicts the opposite

201 Prosser and Keeton says that the same "suggestion"- that is, that "[w]here the defendant would be relieved of responsibility even if the act were to be anticipated, the defendant should be no less relieved when it is unforeseeable"-may be applied to "resolve the apparent confusion" in two further types of cases: first, Henningsen-like cases in which an intervening party fails to protect a child from a dangerous object procured from the defendant; and second, cases in which a third party "fully discovers" the dangerous nature of the object sold by the defendant, and deliberately inflicts this danger on the plaintiff. $I d$. We've argued above that while their "suggestion" just pushes the question of responsibility further back, our model supplies a genuine explanation; this explanation applies equally well to these two further types of cases. We discussed the Henningsen-like cases above. See supra notes 163-66 and accompanying text. Our model provides a similar explanation for the second type of case: where the third party is fully aware of the danger and nevertheless deliberately inflicts it on the plaintiff, the moral abnormality of that intervening cause is higher than the moral abnormality of the original, merely negligent defendant.

202 See Wallinga v. Johnson, 131 N.W.2d 216, 218 (Minn. 1964).

203 See J.H. Welch \& Son Contracting Co. v. Gardner, 392 P.2d 567, 569 (Ariz. 1964) (en banc).

204 McLeod v. Grant Cnty. Sch. Dist. No. 128, 255 P.2d 360, 361 (Wash. 1953) (en banc).

205 Hines v. Garrett, 108 S.E. 690, 691-92 (Va. 1921) (en banc). 
of these cases: if the intervening cause is more abnormal, then it should supersede and break the causal chain, relieving the original wrongdoer of liability.

It should also be noted that courts themselves recognize the exceptional nature of these cases. Despite the fact that criminality normally supersedes the original negligence, courts routinely point out that criminality does not supersede when the original duty was to protect against the harm that was realized. For example, in Hines $v$. Garrett, ${ }^{206}$ a train conductor forgot to stop at a station and left off an eighteen-year-old girl on the tracks a half mile away at night. ${ }^{207}$ As she walked back on the tracks, she was raped by two different men. The Virginia Supreme Court ruled against the railroad, writing that the rule "that no responsibility for a wrong attaches whenever an independent act of a third person intervenes between the negligence complained of and the injury ... does not apply where the very negligence alleged consists of exposing the injured party to the act causing the injury." 208 Similarly, in McLeod v. Grant County School District No. 128, ${ }^{209}$ holding a school responsible for failing to protect a student from being raped in the gymnasium, the court cited the Second Restatement: "If the realizable likelihood that a third person may act in a particular manner is the hazard or one of the hazards which makes the actor negligent, such an act whether innocent, negligent, intentionally tortious or criminal does not prevent the actor from being liable for harm caused thereby." 210

One response to cases of this type would be to concede that the pattern of folk judgments of causation does not explain the law, but to argue that these cases are the rare circumstances in which policy considerations trump the doctrine of proximate causation. After all, it would be absurd to absolve a bailor of responsibility for not locking a safe just because a thief later stole the jewelry entrusted to him. Isn't the job of the bailor specifically to stop thieves from stealing valuables? To insist on proximate cause

206108 S.E. 690 (Va. 1921) (en banc).

207 See id. at 691.

$208 I d$. at 695 (emphasis added).

209255 P.2d 360 (Wash. 1953) (en banc).

$210 I d$. at 365 (citing RESTATEMENT (SECOND) OF TORTS $§ 449$ (AM. L. INST. 1965)).

It would not be enough for a builder to fence off a part of the walk because it was in a dangerous condition, and then give it no more attention. He knows the probabilities of the removal of the barrier by mischievous or disorderly persons, and he should exercise reasonable care to see that it is in place.

J.H. Welch \& Son, 392 P.2d at 571. 
would make it impossible to hold guardians responsible for their negligence.

We, however, prefer a different response. We believe that legal judgments in these cases do in fact reflect folk judgments of causation. ${ }^{211}$ The problem is just that existing empirical theories of folk judgments of causation fail to capture correctly the effect that arises in these cases. Existing empirical theories therefore ought to be modified in the special case where the original wrong committed was a violation of a protective duty. In the modified account, morally abnormal intervening causes supersede less morally abnormal ones, except when the original wrong was the violation of a protective duty.

While there are not yet any studies that back up this modification, we believe it fits with the basic motivation of the model described above. After all, the core motivation behind this model was the assumption that people tend not to consider counterfactuals in which agents perform actions that violate norms. This assumption may hold in general, but we hypothesize that it does not hold in this specific case in which people are focusing on a duty that exists only because of the possibility that other agents may violate a norm. For example, it may be a general fact about people's cognition that they tend not to consider possibilities in which agents violate moral norms by stealing objects from a safe. However, in this specific case in which people are considering a bailor who is obligated to keep a safe locked because of the possibility of theft, they would be strongly drawn to consider that sort of possibility, and the act of stealing from the safe would then fail to supersede. Clearly, this is an empirical hypothesis-much like the many empirical hypotheses that have already been explored within the cognitive science literature on folk judgments of causation-and it could be put to the test using those same methods.

We can also see why the law would make exceptions to the standard rule about normality in these cases. As we argued in Part V, normality gives us a sense of which possibilities a reasonable agent would have taken account of before acting. But when reasonable agents are subject to a protective duty, they must take into account norm violations whose very possibility is the ground of the protective duty. Thus, it would be unreasonable for a bailor entrusted with protective jewels not to consider the possibility

211 In our model, folk judgments of causation are normatively inflected by judgments of normality, but not by every policy consideration that affects responsibility. 
that someone might want to steal those jewels-even though, indeed especially because, this behavior is morally abnormal.

The second set of outlier cases involves intervening causes that are morally less abnormal than the original negligence, and yet nevertheless do supersede. In Goneau v. Minneapolis, St. Paul \& Sault Saint Marie Railway Co., ${ }^{212}$ the brakeman went to fix a defective coupling between two cars. As he was repairing the mechanism, he fell and severely injured himself. ${ }^{213}$ The Minnesota Supreme Court held that the defective coupling was not the proximate cause of the brakeman's injuries. ${ }^{214}$ This result runs counter to our model because the brakeman's fall was morally less abnormal than the original negligence and yet this intervening cause breaks the causal chain, absolving the railroad of responsibility.

Or consider so-called "dart out" cases. In these instances, speeding motorists are not held liable for striking children that suddenly dart onto roads, even though the possibility of such accidents is generally foreseeable.215 Again, this result is inconsistent with our model because the morally less abnormal action of the darting child supersedes the illegal actions of the driver.

Call these "pure coincidence" cases. In such situations, the intervening causes are not the type of events that raises the likelihood of harm. These events merely make the injury possible by ensuring that the original wrong and the victim co-occur in space and time. The negligent installation of defective couplings in Goneau is not the kind of event that raises the probability that brakemen will fall from trains. It merely serves to place the brakeman in a spot where his falling leads to injury. Likewise, in the dart out cases, the speed simply places the car at the spot to hit the child-this is a pure coincidence, not something that makes it more likely that children will be hit. ${ }^{216}$

212191 N.W. 279 (Minn. 1922).

213 See id. at 279.

214 See id. at 281.

215 See, e.g., Howk v. Anderson, 253 N.W. 32, 32 (Iowa 1934); Burlie v. Stephens, 193 P. 684, 685 (Wash. 1920). Though the court in Howk found that the motorist was not bound to anticipate the child darting out, Prosser and Keeton describes such cases as ones in which the risk is generally foreseeable. KEETON ET AL., supra note 16, § 44, at 305-06.

216 For an influential discussion of the relationship between an act and the corresponding likelihood of a particular injury, see generally Guido Calabresi, Concerning Cause and the Law of Torts: An Essay for Harry Kalven, Jr., 43 U. CHI. L. REv. 69, 71 (1975). Then-Professor Calabresi described the notion of "causal link," which obtains between an act and an injury when we believe that the act "will increase the chances that the injury will also occur." Id. In Calabresi's terminology, what we have been calling pure coincidence cases are those in which no causal link obtains between the act and the injury. 
Of course, pure coincidence cases violate Prosser and Keeton's model as well. Intervening causes supersede even when foreseeable. Prosser and Keeton explains away these cases by pointing out that the defendant's actions did not increase the risk of the particular outcome-in Prosser and Keeton's terminology, the defendant's conduct had not "created or increased an unreasonable risk of harm through its intervention," and so the resulting harm was outside "the scope of the [original] risk." 217 Prosser and Keeton never explains why intervening events must increase the risk of harm in order to count as proximate cause. The treatise simply assumes it to be self-evident.

To explain why less abnormal events supersede the original wrongdoing in pure coincidence cases we rely on a policy-based argument. The law absolves the original wrongdoer of responsibility when their actions are not the kind that increases the risk of injury to ensure that the liability of the wrongdoer is not unfairly extended. If the law were to hold wrongdoers liable even when their actions did not increase the risk of injury, it would be treating the wrongdoer as the insurer of every person injured once the wrongdoing happened. 218

Consider the comments of the Minnesota Supreme Court in Goneau. The court argued that the plaintiff's request for compensation "would lead to surprising results." 219 The railroad would be responsible not just when the brakeman fell when trying to fix the coupling. It would be liable even trying to get to the coupling and get back:

[I]t would make the defendant liable if plaintiff had slipped and fallen while walking alongside the train in going from or returning to the caboose. Defendant would become an insurer of plaintiff's safety from the moment the train broke in two until after it had been reunited and was on its way again. ${ }^{220}$

Absolving the original wrongdoer in coincidence cases, therefore, is akin to the New York practice of releasing the negligent fire setter of liability for any but the first building burning down. The law of proximate causation diverges from folk judgments of causation in rare cases when there are especially strong

217 KEETON ET AL., supra note $16, \S 44$, at 303-07.

218 Cf. Calabresi, supra note 216, at 78 (arguing that the requirement of a causal link for liability is "crucial" with respect to the objective of effective deterrence).

219 Goneau, 191 N.W. at 281.

$220 \mathrm{Id}$. 
policy reasons not to impose liability. In these situations, even though there has been a breach of duty, which was the proximate cause of the injuries, the law refrains from imposing liability. As the court in Goneau explained, liability in coincidence cases would amount to holding the wrongdoer to be "an insurer of plaintiff"s safety." ${ }_{221}$ Such a burden is so onerous that even a reasonable person would not expend efforts to guard against it.

\section{B. Concurrent Causation}

Having compared Prosser and Keeton's treatment of intervening causation to our own model, we now move to its discussion of concurrent causation. In concurrent causation, two independent and causally sufficient events co-occur and a certain result is produced. The legal question is whether each of these events counts as a cause.

Prosser and Keeton begins its discussion of concurrent causation by noting that the but-for test for factual causation fails in these cases. ${ }^{222}$ If two fires, each sufficient in itself, burn down a house, neither is a but-for cause of the damage. Extinguish one fire and the house still burns to the ground. Nevertheless, both fires are the cause of the damage-according to folk judgments and legal doctrine.

In response to this unwanted result, Prosser and Keeton observes that courts use an alternate method for determining liability in cases of concurrent causation: courts ask not whether the defendant was a but-for cause of the harm, but rather whether he was a "substantial factor" in bringing it about. ${ }^{223}$ But, Prosser and Keeton cautions, the substantial-factor formulation "can scarcely be called a test" - courts apply no uniform method for determining when a factor is substantial, and the phrase is "neither possible nor desirable to reduce" to more basic terms. ${ }^{224}$ It thus supplies to the jury a kind of "sufficiently intelligible" general heuristic for assigning liability. ${ }^{225}$

We believe that our model sheds light on how courts use the substantial-factor judgments in cases of concurrent causationor as we call them, disjunctive cases. We can, in other words, subject disjunctive cases to systematic analysis. To show how, we

221 Id. at 281.

222 See KeETON, supra note $16, \S 41$, at 266.

223 Id. § 41, at 267.

224 Id.

$225 \mathrm{Id}$. 
divide cases into those where each event is equally normal and those in which one is more normal than the other.

\section{Equal normality.}

In disjunctive cases, our model predicts that equally normal concurrent causes should be regarded as equally causal. The case law straightforwardly bears out our model's prediction: it holds that when two causes each "would have been sufficient to cause the identical result," it is "clear that neither can be absolved from that responsibility." 226 For instance, Prosser and Keeton cites Corey $v$. Havener, ${ }^{227}$ in which the plaintiff was injured when his horse was frightened by two speeding motorcyclists passing on either side.228 The court held that "[i]t makes no difference that there was no concert between them, or that it is impossible to determine what portion of the injury was caused by each." ${ }_{229}$ Instead, that "both of the defendants were wrongdoers" and each was a sufficient cause was enough to hold them both liable. ${ }^{230}$ This is exactly what our model predicts: two equally normal-in this case, equally negligent-concurrent causes are judged to be equally liable for the accident. Like the court in Havener, our model doesn't ask which portion of the actual injury is attributable to which of the causes; it only asks whether the causes are equally normal and independently sufficient to cause the harm.

\section{Unequal normality.}

Prosser and Keeton offers several examples in which two concurrent causes, each sufficient to cause the harm, have differing levels of normality. For instance, "[t]he defendant sets a fire, which merges with a fire from some other [innocent or unknown] source; the combined fires burn the plaintiff's property, but either one would have done it alone." ${ }^{331}$ Or, as in Basko v. Sterling Drug, Inc., ${ }^{232}$ the plaintiff loses eyesight after taking two different drugs, each of which was sufficient to cause blindness. ${ }^{233}$ In that case, one of the drug manufacturers behaved negligently by failing to

\footnotetext{
$226 I d . \S 41$, at $266-67$.

22765 N.E. 69 (Mass. 1902).

228 See id. at 69 .

229 Id.

$230 \mathrm{Id}$.

231 KEETON ET AL., supra note 16 , § 41, at 266-67.

232416 F.2d 417 (2d Cir. 1969).

233 See id.
} 
exercise a duty to warn, while the other had no such duty. ${ }^{234}$ Thus, the two sufficient causes had differing levels of normality.

In cases of unequal normality, the general rule is that the actor who acted wrongly may still be held liable. Prosser and Keeton says: "[W] hen the negligence of a defendant 'concurs' with an act of God, which is to say an unforeseeable force of nature, the defendant is to be held liable." ${ }^{235}$ Similarly, the Second Restatement provides the example of a house destroyed by the merging of two fires: one set by the negligence of Company A and the other of unknown or innocent origins. ${ }^{236}$ According to the Restatement, Company A may be held liable if its negligence is found to be a "substantial factor" in causing the harm. ${ }^{237}$

Holding the wrongdoer liable even in cases where his wrongdoing concurs with an innocent cause seems, from a policy perspective, to be the right result. As Professor Charles Carpenter wrote in one of the first scholarly articles to examine concurrent causation, " $[\mathrm{t}] \mathrm{o}$ excuse the defendant from liability where all the elements of liability required in other cases exist would be to make the defendant a favorite of the law in the concurrent cause cases . . . without warrant." 238

Similarly, Professors Fowler Harper and Fleming James claimed that "negligent conduct will be more effectively deterred by imposing liability than by giving the wrongdoer a windfall in cases where an all-sufficient innocent cause happens to concur with his wrong in producing harm." 239

It is therefore surprising that both courts and legal scholars have come out the other way: they have held that in cases where wrongdoing concurs with an innocent cause, there is no liability. Consider the case of Cook discussed earlier in Part IV.A, in which

234 See id. at 430.

235 KeEton, supra note 16, § 41, at 314; see also Manila Sch. Dist. No. 15 v. Sanders, 289 S.W.2d 529, 532 (Ark. 1956) ("[W]here the negligence of a party concurs with the act of God, then the act of God is no defense.").

236 See RESTATEMENT (SECOND) OF TORTS $§ 432 \mathrm{cmt}$. d (AM. L. INST. 1965).

237 See RESTATEMENT (SECOND) OF TORTS $§ 432 \mathrm{cmt}$. d (AM. L. InST. 1965).

238 Charles E. Carpenter, Concurrent Causation, 83 U. PA. L. REV. 941, 946 (1935).

2392 FOWLER V. HARPER \& FlEMING JAMES, JR., THE LAW OF TORTS 1123 (1956). Along similar lines, Judge Learned Hand held that in situations of negligence concurring with an innocent cause, the wrongdoer should bear the "impossible" burden of showing which portion of the injury is attributable to which cause, effectively securing his total liability: "[W]hen one of the two contributing factors is not the result of an actionable fault[,] the single tortfeasor cannot be allowed to escape through the meshes of a logical net. He is a wrongdoer; let him unravel the casuistries resulting from his wrong." Navigazione Libera Triestina Societa Anonima v. Newtown Creek Towing Co., 98 F.2d 694, 697 (2d Cir. 1938). 
a fire started negligently by the defendant combined with another fire of unknown origin; together, the single merged fire destroyed the plaintiff's property. ${ }^{240}$ The court found that the defendant could not be held liable, and developed an explicit theory of concurrent causation with an innocent event:

[W] here an injury accrues to a person, by the concurrence of two causes, one traceable to another person under such circumstances as to render him liable as a wrongdoer, and the other not traceable to any responsible origin, but is of such efficient or superior force that it would produce the injury regardless of the responsible cause, there is no legal liability. No damage in such circumstances can be traced, with reasonable certainty, to wrongdoing as a producing cause. The one traceable to the wrongdoer is superseded by the other cause or condition, which takes the place of it and becomes, in a physical sense, the proximate antecedent of what follows. ${ }^{241}$

Similarly, New Hampshire Supreme Court Chief Justice Robert Peaslee has argued that in cases in which an "innocent cause would surely have done the damage" for which the defendant's wrongdoing would also have been sufficient, "it is not apparent how the latter can be considered the cause of the loss. Causation is matter of fact, and that which is not in fact causal ought not to be deemed so in law." ${ }_{42}$ So long as the innocent act was "so far complete as to make the result certain to ensue before the defendant's act became operative," the defendant cannot be held liable for his concurrent wrongdoing. ${ }^{243}$ Professor Peter Cane, in describing English common law, goes even further:

In cases where only one of the factors is legally proscribed human conduct, the perpetrator of that conduct is allowed to take advantage of the other factor, whether it is contemporaneous with, precedes or follows the conduct: the law treats

240 See Cook, 74 N.W. at 562.

241 Id. at 566. The Cook holding was significantly undermined by Kingston v. Chicago \& N.W. Railway Co., 211 N.W. 913 (Wis. 1927), was repudiated by the American Law Institute in the Restatement of Torts, and has generally failed to be adopted. See KEETON, supra note $16, \S 41$, at 267 n. 26 .

242 Robert J. Peaslee, Multiple Causation and Damage, 47 HARv. L. REv. 1127, 1130 (1934).

243 Id. 
the other factor as the cause in preference to the legally proscribed conduct." 244

In other words, in all those cases where "only one of the factors is legally culpable human conduct-where, for instance, one is a 'natural' event (i.e., an event not traceable to human agency)the latter will be treated as the cause." 245

Shielding a wrongdoer from liability when his act concurs with an innocent cause is the minority position in American law. The policy reasons of deterring wrongful conduct and avoiding a windfall for wrongdoers have helped to establish the Restatement rule: that a wrongdoer may be found to be a "substantial factor" in causing the harm, and therefore to be held liable, even when his wrongdoing concurs with an innocent cause. ${ }^{246}$ Indeed, some commentators have found the Cook reasoning to be utterly baffling. ${ }^{247}$ But our model helps to explain why, even in the face of these significant policy considerations, there is nevertheless a tendency to see, as the Cook court did, the innocent cause as superseding the wrongdoing.

Recall that in disjunctive cases, more normal events weakly_but do not strongly-supersede less normal events. In other words, folk judgments penalize less normal events by

244 Peter Cane, Responsibility in LAW AND Morality 122 (2002).

245 Id. at 121.

246 See supra notes 235-37 and accompanying text. Note that the Restatement rulethat a wrongdoer acting in concurrence with an innocent cause may be considered the legal cause of the harm if his negligence is found to be a "substantial factor" in producing the damage - makes little sense from the perspective of the legal realist. Recall that realists deny that there is a distinct doctrine of proximate causation; instead, judgments of "causation" are merely proxies for the underlying moral judgments governing liability. See supra Part I. But if that were the case, then courts would be expected to identify the wrongdoer as the straightforward cause in cases in which his wrongdoing concurs with an innocent event: there would simply be no need for shifting the discussion into terms of substantial factors. The very fact that courts analyze cases of concurrent causation in terms of substantial factors - rather than identifying the wrongdoer as the unique causesuggests that their causal judgments aren't, contra the realist, straightforwardly reducible to their moral judgments.

247 See, e.g., Carpenter, supra note 238, at 946:

It would seem clear that if a plaintiff satisfies the requirements of proof of negligence and causation required in other types of tort, he should not fail in the concurrent cause cases merely because he does not or cannot show that another cause which did contribute to his damage was not an innocent cause. . . In determining the liability of the defendant, there is no reason apparent for inquiring into the nature of other causes that contributed to produce the damage in the concurrent cause cases which does not exist in other types of cases. There is no discoverable reason for differentiating the cases [of innocent and negligent concurrent causes]. 
lowering their causal score, but they do not simultaneously raise the causal score of the more normal event (compared to what they would have been if both were normal). This weak supersession in disjunctive cases differs from the strong supersession in conjunctive cases. When an abnormal conjunct supersedes a normal conjunct, the former is not only seen as more causal, but the latter is seen as less causal (compared to what they would have been if both were normal).

Yet the disagreement in the case law and scholarly literature over disjunctive cases of unequal normality may be explained by an underlying disagreement over the status of weak supersession. Those who follow the Cook line might hold that weak supersession counts as supersession for the purposes of proximate causation. In other words, because normal events are seen as more causal than all other factors, they supersede less normal events. Those who follow the majority view, on the other hand, might hold that weak supersession is not real supersession. To supersede, normal events not only have to be seen as more causal than all other factors, but those other factors also have to be seen as less causal. In disjunctive cases, however, this is not so-normal events are seen as more causal, but the causal score of abnormal events does not change.

\section{Summing Up}

As we have seen, Prosser and Keeton takes the standard legal realist line on proximate causation: proximate cause is just another name for "responsible cause." We have also seen that Prosser and Keeton has difficulty explaining the case law it describes. In intervening and concurrent cause cases, its analysis can only be made to fit judicial decisions by warping or rendering meaningless concepts such as "foreseeability" and "substantial factors." Indeed, in many cases, Prosser and Keeton simply admits that it cannot explain the doctrine.

Prosser and Keeton's analysis of proximate causation raises an even larger question mentioned earlier: If proximate causation is just a proxy for judgments of responsibility, why does it even

exist? Courts would seem to be wasting an enormous amount of time and energy on a meaningless doctrine. It would make more sense for them to jettison the doctrine and fold all of their discussion into the question of whether a duty existed which had been breached, as the Third Restatement has done. 
Our approach, by contrast, explains why proximate cause cases exist. In these cases, there are simply too many events that causally contributed to the harm. Since legal responsibility is pegged to the cause (or causes) of the harm, there is a need to select from this very large set the appropriate event (or events). Questions of proximate causation, therefore, are real and urgent: they ask about the existence of a fact whose obtaining is a necessary condition for holding one of the parties responsible.

We have also shown that folk judgments of causation can explain the legal doctrine as described by Prosser and Keeton. The case law generally tracks our model in conjunctive and disjunctive cases. No doubt, our model will need to be refined in the future. But we believe we have showed its plausibility, at least as compared to the realist and formalist positions.

\section{CONCLUSION}

Though most scholars have found legal realism's interpretation of proximate causation irresistible, it is fair to say that many wished that it weren't. Legal realism, after all, is unnerving. If the realists are right and the language of proximate causation is window dressing for unrestricted moral deliberation about responsibility, it is difficult to see how common law adjudication is consistent with the rule of law. Judges would not be following preexisting rules dictating who is responsible for what; they would be using their own moral sensibilities to determine after the fact where liability should lie, all the while pretending to be acting otherwise.

Fortunately, a clear-eyed view of the case law need not delegitimatize common law courts. As we have tried to show, judges who invoke the doctrine of proximate causation are not pretending to follow the rules. They are doing what the rules tell them to do, namely, to engage in ordinary causal reasoning. The conclusions of such reasoning are judgments about which actions caused the relevant harm. These causal judgments are then used as premises in further deliberation about who is legally responsible for the harm in question.

The trick, of course, is to recognize that ordinary causal reasoning is not morality-free reasoning. Whether an action will be selected as the cause of harm normally depends on whether that action has violated a norm. In this sense, the realists were right: judicial behavior in proximate cause cases cannot be understood formalistically. Judges make decisions on the basis of moral 
deliberation. But as we have argued, not all moral deliberation is the same. Judging that someone's actions have violated a norm is not concluding that they are responsible for the harm to which they causally contributed.

Scholars can now have their cake and eat it too. They can happily concede to the realist that judges in proximate cause cases are making moral judgments while siding with the formalist that judges in these cases are also following the rules. And with both camps they can agree that judges are people too: they make decisions about causation and responsibility the way we all do and their opinions capture this familiar form of reasoning, at least a good portion of the time.

Scholars also have a new tool at their disposal for further analysis of proximate cause cases: cognitive science. By contrast to formalists such as Professors Hart and Honoré who used the methods of mid-century Oxford philosophy-intuition pumping and ordinary language analysis-legal scholars can use the new field of cognitive science and the substantial literature it has generated on ordinary judgments of causation. Jurisprudence, therefore, need not confine itself to the armchair-it can run experiments and see how folk judgments line up with the law. 